\title{
A comparative study of co-precipitation and sol-gel synthetic approaches to fabricate cerium-substituted Mg-Al layered double hydroxides with luminescence properties
}

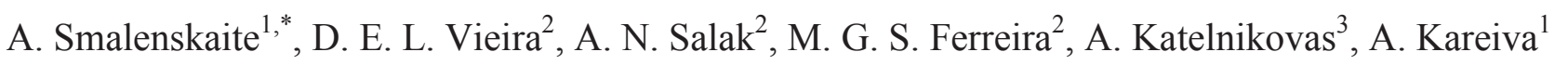 \\ ${ }^{1}$ Department of Inorganic Chemistry, Vilnius University, Naugarduko 24, LT-03225 Vilnius, \\ Lithuania \\ ${ }^{2}$ Department of Materials and Ceramic Engineering and CICECO - Aveiro Institute of Materials, 3810-193 Aveiro, Portugal
${ }^{3}$ Department of Analytical and Environmental Chemistry, Vilnius University, Naugarduko 24, LT- 03225 Vilnius, Lithuania

\begin{abstract}
$\mathrm{Mg} / \mathrm{Al} / \mathrm{Ce}$ layered double hydroxides (LDHs) intercalated with carbonate and hydroxide anions were synthesized using co-precipitation and sol-gel method. The obtained materials were characterized by thermogravimetric (TG) analysis, X-ray diffraction (XRD) analysis, fluorescence spectroscopy (FLS) and scanning electron microscopy (SEM). The chemical composition, microstructure and luminescent properties of these LDHs were investigated and discussed. The $\mathrm{Ce}^{3+}$ substitution effects were investigated in the $\mathrm{Mg}_{3} \mathrm{Al}_{1-x} \mathrm{Ce}_{x} \mathrm{LDHs}$ by changing the $\mathrm{Ce}^{3+}$ concentration in the metal cation layers from 0.05 to $10 \mathrm{~mol} \%$. It was demonstrated, that luminescence properties of cerium-substituted LDHs depend on the morphological features of the host lattice.
\end{abstract}

Keywords: Layered double hydroxides; co-precipitation, sol-gel processing; cerium substitution

effects; luminescent properties

\section{*Corresponding author: E-mail: aurelija.smalenskaite@gmail.com}




\section{Introduction}

Layered double hydroxides (LDHs) are compounds composed of positively charged brucite-like layers with an interlayer gallery containing charge compensating anions and water molecules. The metal cations occupy the centres of shared oxygen octahedra whose vertices contain hydroxide ions that connect to form infinite two-dimensional sheets (Jayaraj et al., 1999; Klemkaite et al., 2011; Bi et al., 2014; Wu et al., 2016). A general chemical formula of an LDH can be expressed as $\left[\mathrm{M}^{2+}{ }_{1}\right.$ $\left.{ }_{x} \mathrm{M}^{3+}{ }_{x}(\mathrm{OH})_{2}\right]^{x+}\left(\mathrm{A}^{y-}\right)_{x / y} \cdot z \mathrm{H}_{2} \mathrm{O}$, where $\mathrm{M}^{2+}$ and $\mathrm{M}^{3+}$ are divalent and trivalent metal cations and $\mathrm{A}^{y-}$ is an intercalated anion which compensates the positive charge created by the partial substitution of $\mathrm{M}^{2+}$ by $\mathrm{M}^{3+}$ in a brucite-type $\mathrm{M}^{2+}(\mathrm{OH})_{2}$ hydroxide. The anions in the interlayer are not strictly limited to their nature. LDHs with many different anionic species have been reported: both inorganic anions (carbonate, chloride, nitrate, sulphate, molybdate, phosphate etc.) and organic anions (terephthalate, acrylate, lactate, etc.) (Miyata et al., 1983; Newman and Jones, 1998; Jaubertie et al., 2006; Klemkaite-Ramanauske et al., 2014; Kuwahara et al., 2016). The commonly found cations are $\mathrm{Mg}^{2+}, \mathrm{Zn}^{2+}, \mathrm{Co}^{2+}, \mathrm{Ni}^{2+}, \mathrm{Cu}^{2+}$ or $\mathrm{Mn}^{2+}$ as divalent cations and $\mathrm{Al}^{3+}, \mathrm{Cr}^{3+}, \mathrm{Co}^{3+}$, $\mathrm{Fe}^{3+}, \mathrm{V}^{3+}, \mathrm{Y}^{3+}$ or $\mathrm{Mn}^{3+}$ among the trivalent ones.

After calcination at temperatures from 300 to $600^{\circ} \mathrm{C}$, an $\mathrm{LDH}$ is converted to the mixed metal oxides (MMO) with high specific surface area and basic properties. An ability of MMO to recover the original layered structure is a property known as „memory effect” (Rives et al., 2001; Klemkaite et al., 2011; Cosano et al., 2016). When MMO is immersed into an aqueous solution which contains some anions, the layered structure can be recovered with those anions intercalated into the interlayer. A more irregular structure of agglomerated flake-like platelets or amorphous phase have been observed after such a reconstruction (Alvarez et al., 2013; Mascolo, 2015).

LDHs have a well-defined layered structure within nanometre scale $(0.3-3 \mathrm{~nm})$ interlayer and contain important functional groups in both the metal hydroxide layers and interlayers. LDHs are widely used in commercial products as adsorbents, catalyst support precursors, anion exchangers, acid residue scavengers, flame retardants, osmosis membranes, sensors (Salak et al., 2012; Carneiro et al., 2015; Li et al., 2016; Lu et al., 2016; Serdechnova et al., 2016). The formation and exploitation of new types of layered double hydroxide (LDH)/polymer NC hydrogels with high performance has been also investigated (Hu and Chen, 2014). Moreover, the LDHs have an $\mathrm{HCl}$ absorption capacity, and may be used as PVC thermal stabilizer (Liu et al., 2008). Recently, considerable attention has been focused on incorporating rare earth elements into LDH host layers to develop new functional materials, which resemble designed optical properties (Binnemans, 2009). LDHs doped with $\mathrm{Tb}^{3+}$ ions in the brucite-like layers were prepared by a simple one-step co- 
precipitation method. When 4-biphenylacetate anions were intercalated in the interlayer space, a big amount of $\mathrm{Tb}^{3+}$ up to about $19 \mathrm{wt} . \%$ was incorporated in the oxygen octahedral layers of the LDH. The luminescence study indicated that energy transfer from the excited state of the intercalated anion guest molecules to $\mathrm{Tb}^{3+}$ centres in the host layers takes place (Gunawan and $\mathrm{Xu}, 2009$ ). The samples (both as-prepared and calcined) containing $\mathrm{Tb}^{3+}$ exhibited green fluorescence (William et al., 2006). Nanosize LDHs doped with $\mathrm{Eu}^{3+}, \mathrm{Yb}^{3+}, \mathrm{Tb}^{3+}$ and $\mathrm{Nd}^{3+}$ were prepared through the microemulsion method (Posati et al., 2012, Vicente et al., 2016). It was concluded that the lanthanide content in the LDH samples depends on the ionic radius of the lanthanide cation and on fabrication conditions. $\mathrm{Eu}^{3+}$ and $\mathrm{Nd}^{3+}$ were incorporated also into hydrocalumite and mayenite (Domínguez, 2011). The $\mathrm{Zn} / \mathrm{Al} / \mathrm{Eu} \mathrm{LDHs}$ were reported as perspective and efficient luminescent materials (Zhang et al., 2014; Gao et al., 2014).

Rare earth doped luminescent materials have drawn increasing attention as potential phosphor materials for use in optical devices (Maqbool et al., 2006; Maqbool et al., 2007; Stanulis et al., 2014; Zabiliute et al., 2014; Skaudzius et al., 2016). The rare-earth metal ions offer the possibility of obtaining blue, green and red colours, which are necessary for RGB devices (Okamoto et al., 1988; Katelnikovas et al., 2012). The organic-inorganic hybrid phosphors have been designed and assembled by the intercalation of salicylic acid, as sensitizer, into the layered lanthanide hydroxides with the compositions of $\mathrm{Gd} / \mathrm{Tb} / \mathrm{Eu} / \mathrm{OH} / \mathrm{NO}_{3} / \mathrm{H}_{2} \mathrm{O}$ through ion-exchange reaction under hydrothermal condition (Liu et al., 2013). The luminescence colour of a rare-earth doped LDH can be easily tuned from green to red due to the energy transfer from the $\mathrm{Tb}^{3+}$ to $\mathrm{Eu}^{3+}$ ions by changing the doping concentration of the activator ions. Luminescent ordered multilayer transparent ultrathin films based on inorganic rare earth elements doped layered double hydroxides $\mathrm{Mg} / \mathrm{Al} / \mathrm{Eu}$ nanosheets and organic ligand were recently fabricated via layer-by-layer assembly method (Zhang et al., 2016).

Vargas et al., 2013, has reported a doping of the layers of a $\mathrm{Zn} / \mathrm{Al} \mathrm{LDH}$ with $\mathrm{Dy}^{3+}$ ions. Photoluminescence spectra of the nitrate intercalated LDH showed a wide emission band with strong intensity in the yellow region (around $574 \mathrm{~nm}$ ), originated from symmetry distortion of the octahedral coordination in dysprosium centres. The emission spectra of Ce-doped different inorganic matrixes are often characterized by a broad emission band with quite symmetric photoluminescence peak at around $530 \mathrm{~nm}$, which is assigned to the $5 \mathrm{~d}^{1}\left({ }^{2} \mathrm{~A}_{1 \mathrm{~g}}\right) \rightarrow 4 \mathrm{f}^{1}\left({ }^{2} \mathrm{~F}_{5 / 2}\right.$ and ${ }^{2} \mathrm{~F}_{7 / 2}$ ) transitions of $\mathrm{Ce}^{3+}$ (Katelnikovas et al., 2007; Katelnikovas et al., 2008; Katelnikovas et al., 2011; Misevicius et al., 2012; Katelnikovas et al., 2013). Cerium-doped hydrotalcite-like precursors were recently synthesized by co-precipitation method (Tamboli et al., 2015). However, these 
compounds were studied only as efficient catalysts for hydrogen production. In this work, the LDHs with the metal cation composition of $\mathrm{Mg}_{3} \mathrm{Al}_{1-x} \mathrm{Ce}_{x}$ (with the $\mathrm{Ce}^{3+}$ substitution rate from 0.05 to 10 mol\%) were synthesized using co-precipitation and sol-gel method. The main aim of this study was to investigate an effect of $\mathrm{Ce}^{3+}$ substitution on crystal structure of the obtained layered double hydroxides and estimate the maximal cerium-to-aluminium substitution rage. The luminescent properties of the $\mathrm{Mg}_{3} \mathrm{Al}_{1-x} \mathrm{Ce}_{x} \mathrm{LDH}$ samples were also investigated in this study for the first time to the best our knowledge.

\section{Experimental}

\subsection{Synthesis by co-precipitation method}

LDH samples were synthesized by adding a mixture of $\mathrm{Mg}\left(\mathrm{NO}_{3}\right)_{2} \cdot 6 \mathrm{H}_{2} \mathrm{O}$ and $\mathrm{Al}\left(\mathrm{NO}_{3}\right)_{3} \cdot 9 \mathrm{H}_{2} \mathrm{O}$ (with molar ratio of 3:1) drop by drop to the solution of $\mathrm{NaHCO}_{3}(1.5 \mathrm{M})$. pH of the resulting solution was measured and kept at 8-9 using $\mathrm{NaOH}(2 \mathrm{M})$ under continuous stirring. To separate the slurry from the solution, the mixture was centrifuged at $3000 \mathrm{rpm}$ for $2 \mathrm{~min}$. The precipitated LDH was washed with distilled water and centrifuged again. Process was repeated three or four times depending on the sample. The formed LDH was dried at $75-80^{\circ} \mathrm{C}$ for $12 \mathrm{~h}$. The mixed-metal oxide (MMO) was achieved by heat treatment at $650^{\circ} \mathrm{C}$ for $4 \mathrm{~h}$. Synthesis of $\mathrm{Mg} / \mathrm{Al} / \mathrm{Ce}$ compounds was performed in the same way as $\mathrm{Mg} / \mathrm{Al} \mathrm{LDH}$, keeping the $\mathrm{pH}$ of the solution about 10 during the synthesis and using $\mathrm{Ce}\left(\mathrm{NO}_{3}\right)_{3} \cdot 6 \mathrm{H}_{2} \mathrm{O}$ as cerium source.

\subsection{Synthesis by sol-gel method}

$\mathrm{The} \mathrm{Mg} / \mathrm{Al}$ and $\mathrm{Mg} / \mathrm{Al} / \mathrm{Ce} \mathrm{LDH}$ samples were synthesised from solutions of the same reagents as those used in the co-precipitation method. The metal nitrates were dissolved in $50 \mathrm{ml}$ of distilled water, then a $0.2 \mathrm{M}$ citric acid solution was added and the mixture was stirred for $1 \mathrm{~h}$ at $80^{\circ} \mathrm{C}$. At the next step, $2 \mathrm{ml}$ of ethylene glycol have been added to the resulted mixture with continues stirring at $150^{\circ} \mathrm{C}$ until the complete evaporation of solvent. The obtained gel was dried at $105^{\circ} \mathrm{C}$ for $24 \mathrm{~h}$. The MMO was obtained by calcination of the gel at $650^{\circ} \mathrm{C}$ for $4 \mathrm{~h}$.

\subsection{Rehydration/Reconstruction}

The MMO powders obtained by co-precipitation and sol-gel methods followed by heat treatment at $650^{\circ} \mathrm{C}$ were reconstructed in water at $50^{\circ} \mathrm{C}$ for $6 \mathrm{~h}$ under stirring $(2 \mathrm{~g}$ of the powder per $40 \mathrm{ml}$ of water). The commercial hydrotalcite PURAL MG63HT powder (Brunsbüttel, Germany) which is chemically a $\mathrm{Mg}_{3} \mathrm{Al} \mathrm{LDH}$ intercalated with $\mathrm{CO}_{3}{ }^{2-}$ was also analysed for comparison.

\subsection{Characterization}


X-ray diffraction (XRD) patterns were recorded using a MiniFlex II diffractometer (Rigaku) in $\mathrm{Cu} \mathrm{K} \mathrm{K}_{\alpha}$ radiation in the $2 \theta$ range from 8 to $80^{\circ}$ (step of $0.02^{\circ}$ ) with the exposition time of $0.4 \mathrm{~s}$ per step. Rietveld analysis of the XRD data was performed using the PANalytical HighScore Plus suite. Thermal analysis was carried out using a simultaneous thermal analyser 6000 (Perkin-Elmer) in air atmosphere at scan rate of $10^{\circ} \mathrm{C} / \mathrm{min}$ over the temperature range of $30^{\circ} \mathrm{C}$ to $900^{\circ} \mathrm{C}$. Excitation and emission spectra were recorded on an Edinburg Instruments FLS 900. Morphology of the LDH powders was investigated using a scanning electron microscope (SEM) Hitachi SU-70. The Fourier transform infrared (FT-IR) spectra were recorded using Perkin-Elmer spectrometer from the LDH samples dispersed in $\mathrm{KBr}$ and pressed into pellets.

\section{Results and discussion}

The XRD pattern of the Mg/Al LDH synthesized by co-precipitation method was found to be essentially similar to that of the commercial hydrotalcite PURAL MG63HT. Three basal reflections typical of an LDH structure were observed: at $2 \theta$ of about $10^{\circ}(003), 23^{\circ}(006)$ and $35^{\circ}(009)$. Besides, two characteristic LDH peaks were clearly seen at about $60.2^{\circ}$ and $61.5^{\circ}$ which correspond to the reflections from the (110) and (113) planes. Evidently, that only amorphous Mg-Al-O gel has formed during the sol-gel preparation of $\mathrm{LDH}$.

As seen from Fig. 1, increasing amount of cerium results in a monotonic decrease of the intensity of these diffraction peaks. In addition, the reflections are shifted to a lower $2 \theta$ range. The observed shift of the (110) and (113) reflections certainly suggests incorporation of this lanthanide ion in metal hydroxide layers of the LDHs prepared by co-precipitation. At the same time, the broad diffraction peaks that can be attributed to a $\mathrm{CeO}_{2}$ phase are seen in the patterns of the LDHs with a non-zero Ce content (Fig. 1). Intensities of these peaks slightly increase with increasing the nominal $\mathrm{Ce}$ content indicating that although the Al-to Ce substitution rate grows, the difference between the nominal and actual rate grows as well.

Thermal treatment of an LDH at elevated temperatures results in loss of interlayer water molecules, charge-compensating anions and dehydroxylation of brucite-like layers. Mg/Al LDH decomposes followed by formation of MMO with the a rock-salt like magnesium oxide as the only crystalline phase (Fig. 2) with Al atoms randomly dispersed throughout the solid, that is often described as an $\mathrm{Mg}(\mathrm{Al}) \mathrm{O}$ phase (Zhao et al., 2012).

The XRD patterns of the $\mathrm{Mg}_{3} \mathrm{Al}$ LDHs (including the Ce-substituted ones) fabricated by coprecipitation method and calcined at $650^{\circ} \mathrm{C}$ are shown in Fig. 3. The formation of poorly crystalline magnesium oxide is evident in all cases. However, the XRD patterns of the samples containing 
cerium exhibited also reflections of a $\mathrm{CeO}_{2}$ phase. The XRD patterns of the $\mathrm{Mg}$-Al-O precursor gels calcined at the same temperature are given in Fig. 4. Apparently, in comparison with the MMO obtained from LDHs prepared by co-precipitation method, the MMO from the sol-gel precursors have formed with higher crystallinity despite of no LDH phase formed during the sol-gel processing. In order to complete crystallization and obtain the material suitable for a quantitative XRD phase analysis (Salak et al., 2013; Carneiro et al., 2015) the formed MMO were heat-treated at higher temperature, namely at $1000^{\circ} \mathrm{C}$ for 6 h. Fig. 3 and Fig. 4 demonstrate the XRD patterns of the resulting products. It is seen that along with the diffraction reflections from $\mathrm{MgO}$ and $\mathrm{CeO}_{2}$, the peaks attributed to the cubic spinel $\mathrm{MgAl}_{2} \mathrm{O}_{4}$ phase are present. The $\mathrm{Mg} /(\mathrm{Al}+\mathrm{Ce})$ molar ratios were estimated from the Rietveld analysis of the XRD data to be $3.22 \pm 0.15$ and $2.92 \pm 0.11$ for the MMO obtained from LDHs prepared by co-precipitation method and for the MMO from the sol-gel derived powders, respectively.

The ability of MMO to (re)form the LDH structure in water or water solutions was tested. The XRD patterns of the LDH samples formed as a result of hydration of the MMO obtained via coprecipitation and sol-gel methods are shown in Fig. 5 and 6, respectively.

The XRD patterns of the $\mathrm{Mg} / \mathrm{Al}$ samples (cerium free) synthesized by co-precipitation, calcined and then immersed in water (Fig. 5) indicate a complete transformation of mixed-metal oxides into an LDH phase. Thus, the reconstruction of layered structure of LDH initially prepared by coprecipitation method occurs in water. The calcined LDHs with a non-zero cerium content demonstrate, however, a less complete regeneration: reflections of the $\mathrm{CeO}_{2}$ phase are observed in the respective XRD patterns. Besides, it is clearly seen that the considerable amount of the amorphous part of the MMO product which contribute to a very broad peak of the XRD background remains uncrystallised.

The samples obtained by rehydration of the sol-gel derived samples show the typical LDH structure (Fig. 6), although no traces of an LDH phase has been detected at any stage of the sol-gel processing. Heat treatment of the sol-gels resulted in high crystalline MMO powders, which were hydroxylated in aqueous media providing well-crystallized LDH phase. According to the XRD patterns presented in Fig. 6, the mixed-metal oxides transformed fully to layered double hydroxides. Interestingly, the formation of LDH from the sol-gel derived powders does not depend on the Ce concentration in the samples. The XRD patterns of the reconstructed (hydroxylated) MMO powders demonstrate the sharp diffraction lines associated with an LDH crystalline phase only. No other crystalline phases have been detected. The (110) reflections of the LDHs are regularly shifted to a lower $2 \theta$ range as the cerium content is increased. Actually, the term "reconstruction" we use is not 
fully correct in the case of LDHs obtained from the sol-gel derived samples. In fact, this is a novel synthesis approach for the fabrication of LDHs, which is based on an aqueous sol-gel processing route.

The basal spacing (which are the distance between the adjacent hydroxide layers) and the lattice parameters of the LDH samples prepared by two different methods are listed in Table 1. The lattice parameter $a$ reflects an average cation-cation distance and can be calculated as $a=2 d_{(110)}$ from the interplanar distance corresponded to the (110) reflections in the brucite-like layers. Parameter $a$ is a function of both size and ratio of cations $\mathrm{M}^{2+}$ and $\mathrm{M}^{3+}$. Parameter $c$ depends mainly on size, charge and orientation of the intercalated species: anions and water molecules (Salak et al, 2014). In order to minimize the experimental error caused by the $2 \theta$ scale shift, $c$-parameter is usually calculated using the interplanar distances of at least two basal reflections: typically, (003) and (006), as $c=3 / 2$ $\left[d_{(003)}+2 d_{(006)}\right]$. The obtained crystallographic data (Table 1) suggest that the observed variation in the lattice parameters of the $\mathrm{Mg} / \mathrm{Al} / \mathrm{Ce} \mathrm{LDHs}$ are caused by substitution of aluminium by cerium in the host layers.

Because of the relatively large ionic radius of $\mathrm{Ce}^{3+}(1.01 \AA)$, substitution of $\mathrm{Al}^{3+}(0.53 \AA)$ by $\mathrm{Ce}^{3+}$ is expected to lead to an expansion of the cation-cation distance in the brucite-like layers (Shannon, 1976). Therefore, as a result of the aluminium-to-cerium substitution, the $a$-parameter grows. Besides, the $c$-parameter increases as well, since because of such a substitution the layers become thicker. The effect of increase of both lattice parameters induced by this isovalent Al-to-Ce substitution is qualitatively the same as that in the case of an increase of the $\mathrm{Mg} / \mathrm{Al}$ cation ratio since $\mathrm{Mg}^{2+}$ is bigger than $\mathrm{Al}^{3+}$. Dependences of lattice parameters of the carbonate-intercalated $\mathrm{Mg} / \mathrm{Al} \mathrm{LDHs}$ on the $\mathrm{Mg} / \mathrm{Al}$ ratio have been reported (Newman and Jones 2001). It has been shown that when the ratio is increased from $1: 1$ to $3.5: 1$, the lattice parameters grow from about 3.02 to $3.07 \AA$ ( $a$-parameter) and from about 22.6 to $23.7 \AA$ (c-parameter). In this work, the $\mathrm{Mg} / \mathrm{Al} / \mathrm{Ce}$ LDHs prepared by co-precipitation were most likely intercalated with $\mathrm{CO}_{3}{ }^{2-}$, as the synthesis was conducted in a $\mathrm{NaHCO}_{3}$ solution (see Experimental). As regards of the $\mathrm{Mg} / \mathrm{Al} / \mathrm{Ce}$ layered double hydroxides formed via hydroxylation of the sol-gel derived MMO, these LDHs can be intercalated with $\mathrm{OH}^{-}$and $\mathrm{CO}_{3}{ }^{2-}$, because the water used for the rehydration procedure was not specially decarbonized. Indeed, the presence of carbonate in the LDH samples prepared using either coprecipitation or via sol-gel method was confirmed by FT-IR study. A spectral band at about 1360 $\mathrm{cm}^{-1}$ associated with $v_{3}^{\prime}$ vibration of $\mathrm{CO}_{3}{ }^{2-}$ was detected in the samples regardless of the preparation method used (Fig. S1 in Supplementary Material). At the same time, the presence of intercalated 
$\mathrm{OH}^{-}$cannot be unambiguously confirmed nor discarded by FT-IR, since one can hardly distinguish between the intercalated hydroxyl groups and those in the brucite-like layers.

In terms of the most compact (flat-laying) orientation, the anions $\mathrm{OH}^{-}$and $\mathrm{CO}_{3}{ }^{2-}$ give the same height of the interlayer gallery, which is equal to the double van der Waals radius of oxygen (Salak et al., 2014). Therefore, the values reported by Newman and Jones can be used as references for our LDHs. It is seen from Table 1 that the obtained lattice parameters of the Ce-substituted $\mathrm{Mg}_{3} \mathrm{Al}$ LDHs are above the aforementioned ranges. The obtained values of both $a$ - and $c$-parameters cannot be associated with any deviation in the $\mathrm{Mg} / \mathrm{Al}$ ratio and certainly indicate the gradual substitution of aluminium by cerium in the brucite-like layers.

The Al-to-Ce isomorphic substitution rate in the obtained $\mathrm{Mg} / \mathrm{Al} / \mathrm{Ce} \mathrm{LDHs}$ was estimated using the expression based on that proposed by Richardson (Richardson, 2012) for case of substitution by two different trivalent cations:

$$
a_{L D H}=a_{M g(O H)_{2}}-\frac{1}{2} \sin \left(\frac{\alpha}{2}\right)\left[r\left(M g^{2+}\right)-(1-x) r\left(A l^{3+}\right)-x r\left(C e^{3+}\right)\right]
$$

Values of the parameter $a$ for $\mathrm{Mg}(\mathrm{OH})_{2}$ and the angle $\alpha$ were taken from the paper by Brindley and Kao (Brindley and Kao, 1984) and the Shannon's ionic radii (Shannon, 1976) were used. The calculated $a$-parameter value for the ideal $\mathrm{Mg} / \mathrm{Al} / \mathrm{Ce} 10 \mathrm{~mol} . \% \mathrm{LDH}(3.089 \AA)$ was compared with the experimentally obtained values. It was found that the real amount of cerium that substituted aluminium in the $\mathrm{Mg} / \mathrm{Al} / \mathrm{Ce} 10 \mathrm{~mol} \% \mathrm{LDHs}$ is about 8 and $6 \mathrm{~mol} . \%$ for the samples prepared by co-precipitation and through sol-gel, respectively.

Based on the obtained results, the methods of fabrication of the $\mathrm{Mg} / \mathrm{Al} / \mathrm{Ce} \mathrm{LDH}$ applied in this work can be compared. As seen from Fig. 1 and Fig. 6, both the co-precipitation method and the sol-gel method provide a gradual Al-to-Ce substitution, although some amount of Ce does not incorporate into the LDH layers and crystallize as cerium oxide. It follows from a comparison of the lattice parameters of LDHs of the same nominal composition but prepared by different methods that when the nominal composition is $5-10 \mathrm{~mol} . \%$ of $\mathrm{Ce}$, the sol-gel method of the $\mathrm{LDH}$ preparation provides higher substitution rates. At the same time, in the case of small-rate substitutions, both methods give similar results. Our idea was the following: if we prove that at least $5 \mathrm{~mol} \%$ of $\mathrm{Al}$ can be substituted by $\mathrm{Ce}$, it guarantees that smaller-rate substitutions are successful a fortiori. In the study of the luminescence properties, where LDHs with the small substitution rates $(1 \mathrm{~mol} . \%$ and less) were used, we considered the LDHs of the same nominal composition but prepared by different methods as chemically equal.

The results of the thermogravimetric analysis of the LDHs synthesised by two different methods are shown in Figs. 7 and 8. The initial mass loss was observed in the temperature ranges of 30- 
$150^{\circ} \mathrm{C}(\sim 18 \%)$ and $30-200^{\circ} \mathrm{C}(\sim 17 \%)$ for the $\mathrm{Mg} / \mathrm{Al} / \mathrm{Ce} 10 \mathrm{~mol} \% \mathrm{LDH}$ prepared by co-precipitation and sol-gel methods, respectively. Some decrease in mass occurs even below $100^{\circ} \mathrm{C}$ because of evolution of the adsorbed water. (Tang et al., 2002). The main decomposition of $\mathrm{Mg} / \mathrm{Al} / \mathrm{Ce} 10$ mol\% sample prepared by co-precipitation method occurs via two steps in the temperature ranges of $290-350^{\circ} \mathrm{C}$ and $350-600^{\circ} \mathrm{C}$. These thermal behaviours result from the loss of the coordinated water and the intercalated anions (in the lower temperature range) and dehydroxylation of the layers followed by collapse of the layered structure (in the higher temperature range). However, the main decomposition of $\mathrm{Mg} / \mathrm{Al} / \mathrm{Ce} 10 \mathrm{~mol} \%$ sample prepared by sol-gel method occurs in one step by monotonic weight decrease in the temperature range of $200-600^{\circ} \mathrm{C}$.

The luminescent properties of the obtained LDHs were also investigated. The luminescence wavelengths of $\mathrm{Ce}^{3+}$ ions change widely from near UV to the red range depending on the nature of the host lattices (Kompe et al., 2003; Li et al., 2003). The emission spectra of $\mathrm{Mg} / \mathrm{Al} / \mathrm{Ce}$ samples fabricated by co-precipitation method is shown in Fig. 9. All powders were excited at $340 \mathrm{~nm}$ for taking the emission spectra. The major emission lines are peaked at $\sim 370-390 \mathrm{~nm}$. The broad bands are attributed to $[\mathrm{Xe}] 5 \mathrm{~d}^{1}-[\mathrm{Xe}] 5 \mathrm{f}^{1}$ transition of $\mathrm{Ce}^{3+}$ ions (Katelnikovas et al., 2010). Surprisingly, the highest intensity of ${ }^{5} \mathrm{D}_{0} \rightarrow{ }^{7} \mathrm{~F}_{2}$ transition was observed for $\mathrm{Mg} / \mathrm{Al} / \mathrm{Ce} 0.05 \mathrm{~mol} \%$ specimen. It turned out that emission intensity decreases with increasing concentration of $\mathrm{Ce}^{3+}$ up to $1 \mathrm{~mol} \%$. The emission maximum was also slightly shifted towards a red spectral region when more $\mathrm{Ce}^{3+}$ was introduced into the host lattice. This is in a good agreement with the results obtained in the $\mathrm{Ce}^{3+}$ doped garnet-type phosphors. In the emission spectra of the sol-gel derived $\mathrm{Mg} / \mathrm{Al} / \mathrm{Ce}$ samples (Fig. 10), the bands are broader and more intensive. Moreover, the maximum of the emission of the LDHs synthesized using sol-gel technique is red shifted $(390-430 \mathrm{~nm})$ in comparison with the LDH phosphors prepared by co-precipitation method. Fig. 9 also shows the emission spectra of the $\mathrm{Mg} / \mathrm{Al} / \mathrm{Ce}$ LDHs synthesized by co-precipitation method, calcined and then reconstructed. It is interesting to note the light output is much stronger in the reconstructed cerium-doped LDHs. Moreover, the red-shift of the emission maximum of the reconstructed $\mathrm{Mg} / \mathrm{Al} / \mathrm{Ce}$ sample is also evident. On the other hand, the highest intensity of ${ }^{5} \mathrm{D}_{0} \rightarrow{ }^{7} \mathrm{~F}_{2}$ transition still is determined for $\mathrm{Mg} / \mathrm{Al} / \mathrm{Ce} 0.05 \mathrm{~mol} \%$ specimen. With further increasing cerium content up to $1 \%$ the concentration quenching was observed (Devaraju et al., 2009).

The morphology of the synthesized $\mathrm{Mg} / \mathrm{Al}$ and $\mathrm{Mg} / \mathrm{Al} / \mathrm{Ce}$ samples was examined using scanning electron microscopy. The characteristic feature of synthesized LDH should be formation of platelike particles with hexagonal shape (Costa et al., 2008; Xu et al., 2010). The rehydration results in (re)generation of the metal hydroxide sheets and the plate-like geometry of the primary particles. 
The SEM micrographs represent the cerium-free $\mathrm{Mg} / \mathrm{Al} \mathrm{LDH}$ powders synthesized by coprecipitation method (Fig. 11). The typical LDH microstructure is evident from this SEM micrograph. The surface is composed of the agglomerated small plate-like particles of 50-100 nm in diameter. After calcination of $\mathrm{Mg} / \mathrm{Al} \mathrm{LDH}$ at $650^{\circ} \mathrm{C}$, the network of spherical nanoparticles (50 to $100 \mathrm{~nm}$ ) have formed. Rehydration of these nanopowders results in formation of plate-like particles with hexagonal shape (Fig. 11c). However, after such a reconstruction, the average particle size of the LDHs increases to $\sim 100-150 \mathrm{~nm}$. The surface morphology of the $\mathrm{Ce}^{3+}$-substituted samples is very similar for all the specimens independent of the substitution rate. The representative SEM micrographs (Fig. 12) of the $\mathrm{Mg} / \mathrm{Al} / \mathrm{Ce} 1 \mathrm{~mol} \%$ sample synthesized by co-precipitation method, calcined and then reconstructed show small fibrous plate-like particles that are aggregated as in the case of a cerium-free LDH sample. The SEM micrographs of the $\mathrm{Mg} / \mathrm{Al} / \mathrm{Ce} 1 \mathrm{~mol} \%$ and $\mathrm{Mg} / \mathrm{Al} / \mathrm{Ce}$ 10 mol\% LDHs fabricated by sol-gel method followed by hydration are shown in Fig. 12. It is seen that the sol-gel derived $\mathrm{Mg} / \mathrm{Al} / \mathrm{Ce} \mathrm{LDHs}$ consist of the larger hexagonally shaped particles varying in size from approximately 150 to $200 \mathrm{~nm}$. The good connectivity between the grains is also observed. These nanograins show tendency to form larger agglomerates. On the whole, nanocrystalline nature of powders with the narrow size distribution of crystallites is observed for all the obtained LDH samples.

The luminescence properties are expected to depend on the closest coordination of $\mathrm{Ce}$ in the layer and hardly on the interlayer distance. The main difference between the LDHs prepared using either co-precipitation method or sol-gel-method is in size and regularity of the crystallites. It is known that the LDH crystallites obtained as a result of (re)hydration of the calcined powders are more irregular than those obtained by co-precipitation. Therefore we consider that the observed differences in the luminescence properties are caused by differences in morphology of the LDHs.

\section{Conclusions}

The $\mathrm{Mg} / \mathrm{Al}$ layered double hydroxides (LDHs) were successfully synthesized by co-precipitation method and using sol-gel preparation technique. To the best our knowledge the latter was successfully applied for production of LDHs for the first time. In this novel aqueous sol-gel processing route, the LDHs were obtained as a result of decomposition (calcination) of the precursor gels at $650^{\circ} \mathrm{C}$ followed by rehydration of the intermediate crystalline MMO powders in water. The same synthesis methods were successfully applied for production of cerium-substituted LDHs $(\mathrm{Mg} / \mathrm{Al} / \mathrm{Ce})$ with the substitution rate from 0.05 to $10 \mathrm{~mol} \%$. It was found that in case of the $\mathrm{Mg} / \mathrm{Al} / \mathrm{Ce} \mathrm{LDHs}$ prepared by co-precipitation followed by calcination, the regeneration rate 
decreases with increase of cerium content, while the conversion of the rehydrated sol-gel derived MMO into LDH does not depend on the concentration of cerium and is close to $100 \%$. The proposed sol-gel synthesis route for LDHs has some benefits over conventional method such as simplicity, high homogeneity of the end products, effectiveness, suitability to study substitution effects for different multinary metal systems and cost efficiency.

The luminescent properties of the obtained LDHs were also investigated. The major emission lines attributed to the $[\mathrm{Xe}] 5 \mathrm{~d}^{1}-[\mathrm{Xe}] 5 \mathrm{f}^{1}$ transition of $\mathrm{Ce}^{3+}$ ions were peaked at $\sim 370-390 \mathrm{~nm}$ and 390 $430 \mathrm{~nm}$ for the $\mathrm{Mg} / \mathrm{Al} / \mathrm{Ce}$ samples fabricated by co-precipitation and by sol-gel methods, respectively. The emission bands were broader, more intensive and red-shifted in the case of the sol-gel derived LDHs.

The typical LDH microstructure was observed in all the obtained samples. The surfaces of the LDHs prepared by co-precipitation were composed of agglomerated small plate-like particles of 50$100 \mathrm{~nm}$ in diameter. After calcination followed by reconstruction (rehydration), the particle size of obtained LDH was observed to increase to 100-150 nm. Even larger particles formed in case of the LDHs prepared by hydration from the sol-gel derived MMO powders.

Luminescence properties of cerium doped LDHs were found to depend on the morphology of the host lattice. The observed compositional behaviours of lattice parameters and the luminescence characteristics indicate the successful isomorphic incorporation of $\mathrm{Ce}^{3+}$ into the brucite-like layers of the $\mathrm{Mg}_{3} \mathrm{Al}_{1-x} \mathrm{Ce}_{x}$ LDHs at least when $x \leq 0.01$.

\section{Acknowledgements}

The work has been done in frame of the project TUMOCS. This project has received funding from the European Union's Horizon 2020 research and innovation programme under the Marie Skłodowska-Curie grant agreement No 645660. The financial support of P2020 COMPETE and FCT-Portugal through project POCI-01-0145-FEDER-016686 - PTDC/CTM-NAN/2418/2014 (NANOCONCOR) is also acknowledged.

\section{References}

Alvarez, M.G., Chimentao, R.J., Barrabes, N., Fottinger, K., Gispert-Guirado, F., Kleymenov, E., Tichit, D., Medina, F., 2013. Structure evolution of layered double hydroxides activated by induced reconstruction. Appl. Clay. Sci. 83-84, 1-11. 
Bi, X., Zhang, H., Dou, L., 2014. Layered Double Hydroxide-based nanocarriers for drug delivery. Pharmaceutics. 6, 298-332.

Binnemans, K., 2009. Lanthanide-Based Luminescent Hybrid Materials. Chem. Rev.109, 42834374.

Brindley, G.W., Kao, C.C., 1984. Structural and IR relations among brucite-like divalent metal hydroxides. Phys. Chem. Minerals 10, 187-191.

Carneiro, J., Caetano, A.F., Kuznetsova, A., Maia, F., Salak, A.N., Tedim, J., Scharnagl, N., Zheludkevich, M.L., Ferreira, M.G.S., 2015. Polyelectrolyte-modified Layered double hydroxide nanocontainers as vehicles for combined inhibitors. RSC Advances 5, 39916-39929.

Cosano, D., Esquinas, C., Jimenez-Sanchidrian, C., Ruiz, J.R., 2016, Use of Raman spectroscopy to assess the efficiency of MgAl mixed oxides in removing cyanide from aqueous solutions. Appl. Surf. Sci. 364, 428-433.

Costa, F., Leuteritz, A., Wagenknecht, U., Jehnichen, D., Häußler, L., Heinrich, G., 2008. Intercalation of $\mathrm{Mg}-\mathrm{Al}$ layered double hydroxide by anionic surfactants: preparation and characterization. Appl. Clay. Sci. 38, 153-164.

Devaraju, M.K., Yin, S., Sato, T., 2009. $\mathrm{Tm}^{3+}$ doped $\mathrm{Y}_{2} \mathrm{O}_{3}$ Nanocrystals: Rapid Hydrothermal Synthesis and Luminescence. Eur. J. Inorg. Chem. 29-30, 4441-4445.

Domínguez, M., Pérez-Bernal, M.E., Ruano-Casero, R.J., Barriga, C., Rives, V., Ferreira, R.A.S., Carlos, L.D., Rocha, J., 2011. Multiwavelength luminescence in lanthanide-doped hydrocalumite and mayenite. Chem. Mater 23, 1993-2004.

Gao, X.R., Lei, L.X., Kang, L.W., Wang, Y.Q., Lian, Y.W., Jiang, K.L., 2014. Synthesis, characterization and optical properties of a red organic-inorganic phosphor based on terephthalate intercalated $\mathrm{Zn} / \mathrm{Al} / \mathrm{Eu}$ layered double hydroxide. J. All. Compd. 585, 703-707.

Gunawan, P., Xu, R., 2009. Lanthanide-doped Layered Double Hydroxides intercalated with sensitizing anions: efficient energy transfer between host and guest layers. J. Phys. Chem. C. $113,17206-17214$.

Hu Z.; Chen G, 2014. Novel nanocomposite hydrogels consisting of layered double hydroxide with ultrahigh tensibility and hierarchical porous structure at low inorganic content. Adv. Mater. 26, $5950-5956$.

Jaubertie, C., Holgado, M.J., San Román, M.S., Rives, V., 2006. Molecular dynamics simulation of the energetics and structure of Layered Double Hydroxides intercalated with carboxylic acids. Chem. Mater. 18, 3114-3121. 
Jayaraj, M.K., Vallabhan, 1991. CPG AC Thin film electroluminescent devices with rare earth doped ZnS. Electrochem. Soc. 138, 512-515.

Katelnikovas, A., Sakirzanovas, S., Dutczak, D., Plewa, J., Enseling, D, Winkler, H., Kareiva, A., Jüstel, T., 2013. Synthesis and optical properties of yellow emitting garnet phosphors for pcLEDs. J. Lumin. 136, 17-25.

Katelnikovas, A., Plewa, J., Sakirzanovas, S., Dutczak, D., Enseling, D., Baur, F., Winkler, H., Kareiva, A., Jüstel, T., 2012. Synthesis and optical properties of green emitting garnet phosphors for phosphor-converted light emitting diode. J. Mater. Chem. 22, 22126-22134.

Katelnikovas, A., Plewa, J., Dutczak, D., Möller S, Enseling, D., Winkler, H., Kareiva, A., Jüstel, T., 2012. Synthesis and optical properties of green emitting garnet phosphors for phosphorconverted light emitting diodes. Opt. Mater. 34, 1195-1201.

Katelnikovas, A., Jurkevicius, J., Kazlauskas, K., Vitta, P., Jüstel, T., Kareiva, A., Zukauskas, A., Tamulaitis, G., 2011. Efficient Cerium-Based Sol-Gel Derived Phosphors in Different Garnet Matrices for Light-Emitting Diodes. J. All. Compd. 509, 6247-6251.

Katelnikovas, A., Bareika, T., Vitta, P., Justel, T., Winkler, H., Kareiva, A., Zukauskas, A., Tamulaitis, G., 2010. Warm-White Light Emitting Diodes. Opt. Mater. 32, 1261-1265.

Katelnikovas, A., Justel, T., Uhlich, D., Jorgensen, J.E., Sakirzanovas, S., Kareiva, A., 2008. Caracterization of cerium-doped ytrium aluminium garnet nanopowders synthesised via sol-gel process. Chem. Eng. Comm. 195, 758-769.

Katelnikovas, A., Vitta, P., Pobedinskas, P., Tamulaitis, G., Zukauskas, A., Jørgensen, J.E., Kareiva, A., 2007. Photoluminescence in sol-gel-derived YAG: Ce phosphors. J. Cryst. Growth. $304,361-368$.

Klemkaite-Ramanauske, K., Zilinskas, A., Taraskevicius, R., Khinsky, A., Kareiva, A., 2014. Preparation of $\mathrm{Mg} / \mathrm{Al}$ layered double hydroxide (LDH) with structurally embedded molybdate ions and application as a catalyst for the synthesis of 2-adamantylidene(phenyl)amine schiff Base. Polyhedron. 68, 340-345.

Klemkaite, K., Prosycevas, I., Taraskevicius, R., Khinsky, A., Kareiva, A., 2011. Synthesis and characterization of layered double hydroxides with different cations ( $\mathrm{Mg}, \mathrm{Co}, \mathrm{Ni}, \mathrm{Al})$, decomposition and reformation of mixed metal oxides to layered structures. Centr. Eur. J. Chem. 9, $275-282$.

Klemkaite, K., Khinsky, A., Kareiva, A., 2011. Reconstitution effect of Mg/Ni/Al Layered Double Hydroxide. Mater. Lett. 65, 388-391. 
Kömpe, K., Borchert, H., Storz, J., Lobo, A., Adam, S., Möller, T., Haase, M., 2003. Nanoparticles with 70 \% Photoluminescence Quantum Yield. Angew. Chem. Int. Ed. 42, 5513-5516.

Kuwahara, Y., Tamagawa, S., Fujitani, T., Yamashita, H., 2016. Removal of phosphate from aqueous solution using Layered Double Hydroxide prepared from waste iron-making slag. Bull. Chem. Soc. Jpn. 89, 472-480.

Lu, P., Liang, S., Qiu, L., Gao, Y.S., Wang, Q., 2016. Layered double hydroxide/graphene oxide hybrid incorporated polysulfone substrate for thin-film nanocomposite forward osmosis membranes. J. Membr. Sci. 504, 196-205.

Li, H.J., Su, X.Y., Bai. C.H., Xu, Y.Q., Pei, Z.C., Sun, S.G., 2016. Graphene based sensor for environmental monitoring of $\mathrm{NO}_{2}$. Sensors. Actuat B-Chemical. 225, 109-114.

Liu, L.L., Xia, D., Liu, W.S., Tang, Y., 2013. Initial theoretical evaluation of pore structure for metal-organic frameworks. Chin. J. Inorg. Chem. 29, 1663-1667.

Li, F.Y., Xia, Z.Q., Yang, S.P., Gao, S.Y., 2004. Synthesis of single-phase nanocrystalline garnet phosphor derived from gel-network-coprecipitation. J. Mater. Sci. 39, 4711-4713.

Liu J.; Chen G.; Yang J., 2008. Preparation and characterization of poly (vinyl chloride)/layered double hydroxide nanocomposites with enhanced thermal stability. Polymer. 49, 3923-3927.

Mascolo, G., Mascolo, M.C., 2015. On the synthesis of layered double hydroxides (LDH) by reconstruction, method based on the "memory effect". Microporous and Mesoporous Materials. $214,246-248$.

Maqbool, M., Ahmad, I., Richardson, H.H., Kordesch, M.E., 2007. Direct ultraviolet excitation of an amorphous AIN: praseodymium phosphor by codoped $\mathrm{Gd}^{3+}$ cathodoluminescence. Appl. Phys. Lett. 91, 193511(1-3).

Maqbool, M., 2006. Luminescence from thulium and samarium doped amorphous AlN thin films deposited by RF magnetron sputtering and the effect of thermal activation on luminescence. Eur. Phys. J. Appl. Phys. 34, 31-34.

Misevicius. M., Scit, O., Grigoraviciute-Puroniene, I., Degutis, G., Bogdanoviciene, I., Kareiva, A., 2012. Synthesis, hydration and thermal stability of hydrates in strontium-aluminate cement. Ceram. Int. 38, 5915-5924.

Miyata, S., 1983. Anion-exchange properties of hydrotalcite-like compounds. Clays. Clay. Min. 31, 305-314.

Newman, S.P., Jones, W., 1998. Synthesis, characterization and applications of layered double hydroxides containing organic guests. New. J. Chem. 22, 105-115. 
Newman, S.P., Jones, W., 2001. Layered double hydroxides as templates for the formation of supramolecular structures. Supramolecular Organization and Materials Design, ed. W. Jones and C. N. R. Rao, Editors, 295-331, Cambridge University Press, Cambridge.

Okamoto, K., Yoshimi, T., Miura, S., 1988. TbOF complex centers in ZnS thin-film electroluminescent devices. Appl. Phys. Lett. 53, 678-680.

Posati, T., Costantino, F., Latterini, L., Nocchetti, M., Paolantoni, M., Tarpani, L., 2012. Hydrotalcite-like materials as precursors of catalysts to produce hydrogen from methanol. Inorg. Chem. 51, 13229-13236.

Richardson, I.G., 2012. The importance of proper crystal-chemical and geometrical reasoning demonstrated using layered single and double hydroxides. Acta Cryst. Sect. B 69, 150-162.

Rives, V., 2001. Layered Double Hydroxides: Present and Future: book. Nova. Science. Publishers., New York.

Salak A.N., Tedim J., Kuznetsova A.I., Ribeiro J.L., Vieira L.G., Zheludkevich M.L., Ferreira M.G.S., 2012. Comparative x-ray diffraction and infrared spectroscopy study of Zn-Al layered double hydroxides: vanadate vs nitrate, Chem. Phys. 397, 102-108.

Salak, A.N., Tedim, J., Kuznetsova, A.I., Vieira, L.G., Ribeiro, J.L., Zheludkevich, M.L., Ferreira, M.G.S., 2013. Thermal behavior of layered double hydroxide Zn-Al-pyrovanadate: composition, structure transformations, recovering ability. J. Phys. Chem. C 117, $4152-$ 4157.

Salak, A.N., Lisenkov, A.D., Zheludkevich, M.L., Ferreira, M.G.S., 2014. Carbonate-free Zn-Al (1:1) layered double hydroxide film directly grown on zinc-aluminum alloy coating. ECS Electrochem. Lett. 3, C9-C11.

Serdechnova, M., Salak, A.N., Barbosa, F.S., Vieira, D.E.L., Tedim, J., Zheludkevich, M.L., Ferreira, M.G.S., 2016. Interlayer intercalation and arrangement of 2mercaptobenzothiazolate and 1,2,3-benzotriazolate anions in layered double hydroxides: in situ X-ray diffraction study. J. Solid State Chem. 233, 158-165.

Shannon, R.D., 1976. Revised effective ionic radii and systematic studies of interatomic distances in halides and chalcogenides. Acta. Crystallogr. Sec. A 32, 751-767.

Skaudzius, R., Juestel, T., Kareiva, A., 2016. Study of $\mathrm{Eu}^{3+}$ and $\mathrm{Tm}^{3+}$ substitution effects in sol-gel fabricated calcium hydroxyapatite. Mater. Chem. Phys. 170, 229-238.

Stanulis, A., Katelnikovas, A., Enseling, D., Dutczak, D., Sakirzanovas, S., Van Bael, M., Hardy, A., Kareiva, A., Jüstel, T., 2014. Luminescence properties of $\mathrm{Sm}^{3+}$-doped alkaline earth orthostannates. Opt. Mater. 36, 1146-1152. 
Tamboli, A.H., Jadhav, AR., Chung, W.J., Kim, H., 2015. Catalyst for hydrogen production from sodium borohydride hydrolysis. Energy 93, 955-962.

Vargas, D.R.M., Oviedo, M.J., Lisboa, F.D., Wypych, F., Hirata, G.A., 2013. Phosphor dysprosium-doped Layered Double Hydroxides exchanged with different organic functional groups. J. Nanomater. Art. ID 730153, 1-8.

Vicente, P., Pérez-Bernal, M.E., Ruano-Casero, R.J., Ananias, D., Almeida Paz, F.A., Rocha, J., Rives, V., 2016. Luminescence properties of lanthanide-containing layered double hydroxides. Microporous and Mesoporous Materials 226, 209-220.

William, M. Y., Shionoya, S., Yamamoto, H., 2006. Fundamentals of Phosphors. CRC. Press. Inc, Ltd. Boca Raton. FL, 335.

Wu, J., Ren, Z.Y., Du, S.C., Kong, L.J., Liu, B.W., Xi, W., Zhu, J.Q., Fu, H.G., 2016. Dehydrated layered double hydroxides: Alcohothermal synthesis and oxygen evolution activity. Nano Res. 9, 713-725.

Xu, Z.P., Braterman, P.S., 2010. Synthesis, structure and morphology of organic layered double hydroxide (LDH) hybrids: Comparison between aliphatic anions and their oxygenated analogist. Appl. Clay. Sci. 48, 235-242.

Yang, W., Kim, Y., Liu, P., Sahimi, M., Tsotsis, T., 2002. A study by in situ technique of the thermal evolution of the structure of a $\mathrm{Mg}-\mathrm{Al}-\mathrm{CO}_{3}$ layered double hydroxide. Chem. Eng. Sci. 57, 2945-2953.

Zabiliute, A., Butkute, S., Zukauskas, A., Vitta P., Kareiva, A., 2014. Sol-gel synthesized far-red chromium-doped garnet phosphors for phosphor-conversion light-emitting diodes that meet the photomorphogenetic needs of plants. Appl. Optics. 53, 907-914.

Zhang, W.J., Li, Y.L., Fan, H.X., 2016. Lanthanide luminescence for biomedical analyses and imaging. Opt. Mater. 51, 78-83.

Zhang, Z., Chen, G.M., Liu, J.G., 2014. Tuneable photoluminescence of europium-doped layered double hydroxides intercalated by coumarin-3-carboxylate. RSC Adv. 4, 7991-7997.

Zhao, Y., Li, F., Zhang, R., Evans, D.G., Duan, X., 2002. Preparation of layered double-hydroxide nanomaterials with a uniform crystallite size using a new method involving separate nucleation and aging steps. Chem. Mater. 14, 4286-4291. 


\title{
A comparative study of co-precipitation and sol-gel synthetic approaches to fabricate cerium-substituted Mg-Al layered double hydroxides with luminescence properties
}

\author{
A. Smalenskaite ${ }^{1, *}$, D. E. L. Vieira ${ }^{2}$, A. N. Salak ${ }^{2}$, M. G. S. Ferreira ${ }^{2}$, A. Katelnikovas ${ }^{3}$, A. Kareiva ${ }^{1}$ \\ ${ }^{1}$ Department of Inorganic Chemistry, Vilnius University, Naugarduko 24, LT-03225 Vilnius, \\ Lithuania \\ ${ }^{2}$ Department of Materials and Ceramic Engineering and CICECO - Aveiro Institute of Materials, \\ 3810-193 Aveiro, Portugal \\ ${ }^{3}$ Department of Analytical and Environmental Chemistry, Vilnius University, Naugarduko 24, LT- \\ 03225 Vilnius, Lithuania
}

\begin{abstract}
$\mathrm{Mg} / \mathrm{Al} / \mathrm{Ce}$ layered double hydroxides (LDHs) intercalated with carbonate and hydroxide anions were synthesized using co-precipitation and sol-gel method. The obtained materials were characterized by thermogravimetric (TG) analysis, X-ray diffraction (XRD) analysis, fluorescence spectroscopy (FLS) and scanning electron microscopy (SEM). The chemical composition, microstructure and luminescent properties of these LDHs were investigated and discussed. The $\mathrm{Ce}^{3+}$ substitution effects were investigated in the $\mathrm{Mg}_{3} \mathrm{Al}_{1-x} \mathrm{Ce}_{x} \mathrm{LDHs}$ by changing the $\mathrm{Ce}^{3+}$ concentration in the metal cation layers from 0.05 to $10 \mathrm{~mol} \%$. It was demonstrated, that luminescence properties of cerium-substituted LDHs depend on the morphological features of the host lattice.
\end{abstract}

Keywords: Layered double hydroxides; co-precipitation, sol-gel processing; cerium substitution effects; luminescent properties

*Corresponding author: E-mail: aurelija.smalenskaite@gmail.com 


\section{Introduction}

Layered double hydroxides (LDHs) are compounds composed of positively charged brucite-like layers with an interlayer gallery containing charge compensating anions and water molecules. The metal cations occupy the centres of shared oxygen octahedra whose vertices contain hydroxide ions that connect to form infinite two-dimensional sheets (Jayaraj et al., 1999; Klemkaite et al., 2011; Bi et al., 2014; Wu et al., 2016). A general chemical formula of an LDH can be expressed as $\left[\mathrm{M}^{2+}{ }_{1}\right.$ $\left.{ }_{x} \mathrm{M}^{3+}{ }_{x}(\mathrm{OH})_{2}\right]^{x+}\left(\mathrm{A}^{y-}\right)_{x / y} \cdot z \mathrm{H}_{2} \mathrm{O}$, where $\mathrm{M}^{2+}$ and $\mathrm{M}^{3+}$ are divalent and trivalent metal cations and $\mathrm{A}^{y-}$ is an intercalated anion which compensates the positive charge created by the partial substitution of $\mathrm{M}^{2+}$ by $\mathrm{M}^{3+}$ in a brucite-type $\mathrm{M}^{2+}(\mathrm{OH})_{2}$ hydroxide. The anions in the interlayer are not strictly limited to their nature. LDHs with many different anionic species have been reported: both inorganic anions (carbonate, chloride, nitrate, sulphate, molybdate, phosphate etc.) and organic anions (terephthalate, acrylate, lactate, etc.) (Miyata et al., 1983; Newman and Jones, 1998; Jaubertie et al., 2006; Klemkaite-Ramanauske et al., 2014; Kuwahara et al., 2016). The commonly found cations are $\mathrm{Mg}^{2+}, \mathrm{Zn}^{2+}, \mathrm{Co}^{2+}, \mathrm{Ni}^{2+}, \mathrm{Cu}^{2+}$ or $\mathrm{Mn}^{2+}$ as divalent cations and $\mathrm{Al}^{3+}, \mathrm{Cr}^{3+}, \mathrm{Co}^{3+}$, $\mathrm{Fe}^{3+}, \mathrm{V}^{3+}, \mathrm{Y}^{3+}$ or $\mathrm{Mn}^{3+}$ among the trivalent ones.

After calcination at temperatures from 300 to $600^{\circ} \mathrm{C}$, an $\mathrm{LDH}$ is converted to the mixed metal oxides (MMO) with high specific surface area and basic properties. An ability of MMO to recover the original layered structure is a property known as „memory effect” (Rives et al., 2001; Klemkaite et al., 2011; Cosano et al., 2016). When MMO is immersed into an aqueous solution which contains some anions, the layered structure can be recovered with those anions intercalated into the interlayer. A more irregular structure of agglomerated flake-like platelets or amorphous phase have been observed after such a reconstruction (Alvarez et al., 2013; Mascolo, 2015).

LDHs have a well-defined layered structure within nanometre scale $(0.3-3 \mathrm{~nm})$ interlayer and contain important functional groups in both the metal hydroxide layers and interlayers. LDHs are widely used in commercial products as adsorbents, catalyst support precursors, anion exchangers, acid residue scavengers, flame retardants, osmosis membranes, sensors (Salak et al., 2012; Carneiro et al., 2015; Li et al., 2016; Lu et al., 2016; Serdechnova et al., 2016). The formation and exploitation of new types of layered double hydroxide (LDH)/polymer NC hydrogels with high performance has been also investigated (Hu and Chen, 2014). Moreover, the LDHs have an $\mathrm{HCl}$ absorption capacity, and may be used as PVC thermal stabilizer (Liu et al., 2008). Recently, considerable attention has been focused on incorporating rare earth elements into LDH host layers to develop new functional materials, which resemble designed optical properties (Binnemans, 2009). LDHs doped with $\mathrm{Tb}^{3+}$ ions in the brucite-like layers were prepared by a simple one-step co- 
precipitation method. When 4-biphenylacetate anions were intercalated in the interlayer space, a big amount of $\mathrm{Tb}^{3+}$ up to about $19 \mathrm{wt} . \%$ was incorporated in the oxygen octahedral layers of the LDH. The luminescence study indicated that energy transfer from the excited state of the intercalated anion guest molecules to $\mathrm{Tb}^{3+}$ centres in the host layers takes place (Gunawan and $\mathrm{Xu}, 2009$ ). The samples (both as-prepared and calcined) containing $\mathrm{Tb}^{3+}$ exhibited green fluorescence (William et al., 2006). Nanosize LDHs doped with $\mathrm{Eu}^{3+}, \mathrm{Yb}^{3+}, \mathrm{Tb}^{3+}$ and $\mathrm{Nd}^{3+}$ were prepared through the microemulsion method (Posati et al., 2012, Vicente et al., 2016). It was concluded that the lanthanide content in the LDH samples depends on the ionic radius of the lanthanide cation and on fabrication conditions. $\mathrm{Eu}^{3+}$ and $\mathrm{Nd}^{3+}$ were incorporated also into hydrocalumite and mayenite (Domínguez, 2011). The $\mathrm{Zn} / \mathrm{Al} / \mathrm{Eu} \mathrm{LDHs}$ were reported as perspective and efficient luminescent materials (Zhang et al., 2014; Gao et al., 2014).

Rare earth doped luminescent materials have drawn increasing attention as potential phosphor materials for use in optical devices (Maqbool et al., 2006; Maqbool et al., 2007; Stanulis et al., 2014; Zabiliute et al., 2014; Skaudzius et al., 2016). The rare-earth metal ions offer the possibility of obtaining blue, green and red colours, which are necessary for RGB devices (Okamoto et al., 1988; Katelnikovas et al., 2012). The organic-inorganic hybrid phosphors have been designed and assembled by the intercalation of salicylic acid, as sensitizer, into the layered lanthanide hydroxides with the compositions of $\mathrm{Gd} / \mathrm{Tb} / \mathrm{Eu} / \mathrm{OH} / \mathrm{NO}_{3} / \mathrm{H}_{2} \mathrm{O}$ through ion-exchange reaction under hydrothermal condition (Liu et al., 2013). The luminescence colour of a rare-earth doped LDH can be easily tuned from green to red due to the energy transfer from the $\mathrm{Tb}^{3+}$ to $\mathrm{Eu}^{3+}$ ions by changing the doping concentration of the activator ions. Luminescent ordered multilayer transparent ultrathin films based on inorganic rare earth elements doped layered double hydroxides $\mathrm{Mg} / \mathrm{Al} / \mathrm{Eu}$ nanosheets and organic ligand were recently fabricated via layer-by-layer assembly method (Zhang et al., 2016).

Vargas et al., 2013, has reported a doping of the layers of a $\mathrm{Zn} / \mathrm{Al} \mathrm{LDH}$ with $\mathrm{Dy}^{3+}$ ions. Photoluminescence spectra of the nitrate intercalated LDH showed a wide emission band with strong intensity in the yellow region (around $574 \mathrm{~nm}$ ), originated from symmetry distortion of the octahedral coordination in dysprosium centres. The emission spectra of Ce-doped different inorganic matrixes are often characterized by a broad emission band with quite symmetric photoluminescence peak at around $530 \mathrm{~nm}$, which is assigned to the $5 \mathrm{~d}^{1}\left({ }^{2} \mathrm{~A}_{1 \mathrm{~g}}\right) \rightarrow 4 \mathrm{f}^{1}\left({ }^{2} \mathrm{~F}_{5 / 2}\right.$ and ${ }^{2} \mathrm{~F}_{7 / 2}$ ) transitions of $\mathrm{Ce}^{3+}$ (Katelnikovas et al., 2007; Katelnikovas et al., 2008; Katelnikovas et al., 2011; Misevicius et al., 2012; Katelnikovas et al., 2013). Cerium-doped hydrotalcite-like precursors were recently synthesized by co-precipitation method (Tamboli et al., 2015). However, these 
compounds were studied only as efficient catalysts for hydrogen production. In this work, the LDHs with the metal cation composition of $\mathrm{Mg}_{3} \mathrm{Al}_{1-x} \mathrm{Ce}_{x}$ (with the $\mathrm{Ce}^{3+}$ substitution rate from 0.05 to 10 mol\%) were synthesized using co-precipitation and sol-gel method. The main aim of this study was to investigate an effect of $\mathrm{Ce}^{3+}$ substitution on crystal structure of the obtained layered double hydroxides and estimate the maximal cerium-to-aluminium substitution rage. The luminescent properties of the $\mathrm{Mg}_{3} \mathrm{Al}_{1-x} \mathrm{Ce}_{x} \mathrm{LDH}$ samples were also investigated in this study for the first time to the best our knowledge.

\section{Experimental}

\subsection{Synthesis by co-precipitation method}

LDH samples were synthesized by adding a mixture of $\mathrm{Mg}\left(\mathrm{NO}_{3}\right)_{2} \cdot 6 \mathrm{H}_{2} \mathrm{O}$ and $\mathrm{Al}\left(\mathrm{NO}_{3}\right)_{3} \cdot 9 \mathrm{H}_{2} \mathrm{O}$ (with molar ratio of 3:1) drop by drop to the solution of $\mathrm{NaHCO}_{3}(1.5 \mathrm{M})$. pH of the resulting solution was measured and kept at 8-9 using $\mathrm{NaOH}(2 \mathrm{M})$ under continuous stirring. To separate the slurry from the solution, the mixture was centrifuged at $3000 \mathrm{rpm}$ for $2 \mathrm{~min}$. The precipitated LDH was washed with distilled water and centrifuged again. Process was repeated three or four times depending on the sample. The formed LDH was dried at $75-80^{\circ} \mathrm{C}$ for $12 \mathrm{~h}$. The mixed-metal oxide (MMO) was achieved by heat treatment at $650^{\circ} \mathrm{C}$ for $4 \mathrm{~h}$. Synthesis of $\mathrm{Mg} / \mathrm{Al} / \mathrm{Ce}$ compounds was performed in the same way as $\mathrm{Mg} / \mathrm{Al} \mathrm{LDH}$, keeping the $\mathrm{pH}$ of the solution about 10 during the synthesis and using $\mathrm{Ce}\left(\mathrm{NO}_{3}\right)_{3} \cdot 6 \mathrm{H}_{2} \mathrm{O}$ as cerium source.

\subsection{Synthesis by sol-gel method}

$\mathrm{The} \mathrm{Mg} / \mathrm{Al}$ and $\mathrm{Mg} / \mathrm{Al} / \mathrm{Ce} \mathrm{LDH}$ samples were synthesised from solutions of the same reagents as those used in the co-precipitation method. The metal nitrates were dissolved in $50 \mathrm{ml}$ of distilled water, then a $0.2 \mathrm{M}$ citric acid solution was added and the mixture was stirred for $1 \mathrm{~h}$ at $80^{\circ} \mathrm{C}$. At the next step, $2 \mathrm{ml}$ of ethylene glycol have been added to the resulted mixture with continues stirring at $150^{\circ} \mathrm{C}$ until the complete evaporation of solvent. The obtained gel was dried at $105^{\circ} \mathrm{C}$ for $24 \mathrm{~h}$. The MMO was obtained by calcination of the gel at $650^{\circ} \mathrm{C}$ for $4 \mathrm{~h}$.

\subsection{Rehydration/Reconstruction}

The MMO powders obtained by co-precipitation and sol-gel methods followed by heat treatment at $650^{\circ} \mathrm{C}$ were reconstructed in water at $50^{\circ} \mathrm{C}$ for $6 \mathrm{~h}$ under stirring $(2 \mathrm{~g}$ of the powder per $40 \mathrm{ml}$ of water). The commercial hydrotalcite PURAL MG63HT powder (Brunsbüttel, Germany) which is chemically a $\mathrm{Mg}_{3} \mathrm{Al} \mathrm{LDH}$ intercalated with $\mathrm{CO}_{3}{ }^{2-}$ was also analysed for comparison.

\subsection{Characterization}


X-ray diffraction (XRD) patterns were recorded using a MiniFlex II diffractometer (Rigaku) in $\mathrm{Cu} \mathrm{K} \mathrm{K}_{\alpha}$ radiation in the $2 \theta$ range from 8 to $80^{\circ}$ (step of $0.02^{\circ}$ ) with the exposition time of $0.4 \mathrm{~s}$ per step. Rietveld analysis of the XRD data was performed using the PANalytical HighScore Plus suite. Thermal analysis was carried out using a simultaneous thermal analyser 6000 (Perkin-Elmer) in air atmosphere at scan rate of $10^{\circ} \mathrm{C} / \mathrm{min}$ over the temperature range of $30^{\circ} \mathrm{C}$ to $900^{\circ} \mathrm{C}$. Excitation and emission spectra were recorded on an Edinburg Instruments FLS 900. Morphology of the LDH powders was investigated using a scanning electron microscope (SEM) Hitachi SU-70. The Fourier transform infrared (FT-IR) spectra were recorded using Perkin-Elmer spectrometer from the LDH samples dispersed in $\mathrm{KBr}$ and pressed into pellets.

\section{Results and discussion}

The XRD pattern of the Mg/Al LDH synthesized by co-precipitation method was found to be essentially similar to that of the commercial hydrotalcite PURAL MG63HT. Three basal reflections typical of an LDH structure were observed: at $2 \theta$ of about $10^{\circ}(003), 23^{\circ}(006)$ and $35^{\circ}(009)$. Besides, two characteristic LDH peaks were clearly seen at about $60.2^{\circ}$ and $61.5^{\circ}$ which correspond to the reflections from the (110) and (113) planes. Evidently, that only amorphous Mg-Al-O gel has formed during the sol-gel preparation of $\mathrm{LDH}$.

As seen from Fig. 1, increasing amount of cerium results in a monotonic decrease of the intensity of these diffraction peaks. In addition, the reflections are shifted to a lower $2 \theta$ range. The observed shift of the (110) and (113) reflections certainly suggests incorporation of this lanthanide ion in metal hydroxide layers of the LDHs prepared by co-precipitation. At the same time, the broad diffraction peaks that can be attributed to a $\mathrm{CeO}_{2}$ phase are seen in the patterns of the LDHs with a non-zero Ce content (Fig. 1). Intensities of these peaks slightly increase with increasing the nominal Ce content indicating that although the Al-to Ce substitution rate grows, the difference between the nominal and actual rate grows as well.

Thermal treatment of an LDH at elevated temperatures results in loss of interlayer water molecules, charge-compensating anions and dehydroxylation of brucite-like layers. Mg/Al LDH decomposes followed by formation of MMO with the a rock-salt like magnesium oxide as the only crystalline phase (Fig. 2) with Al atoms randomly dispersed throughout the solid, that is often described as an $\mathrm{Mg}(\mathrm{Al}) \mathrm{O}$ phase (Zhao et al., 2012).

The XRD patterns of the $\mathrm{Mg}_{3} \mathrm{Al}$ LDHs (including the Ce-substituted ones) fabricated by coprecipitation method and calcined at $650^{\circ} \mathrm{C}$ are shown in Fig. 3. The formation of poorly crystalline magnesium oxide is evident in all cases. However, the XRD patterns of the samples containing 
cerium exhibited also reflections of a $\mathrm{CeO}_{2}$ phase. The XRD patterns of the $\mathrm{Mg}$-Al-O precursor gels calcined at the same temperature are given in Fig. 4. Apparently, in comparison with the MMO obtained from LDHs prepared by co-precipitation method, the MMO from the sol-gel precursors have formed with higher crystallinity despite of no LDH phase formed during the sol-gel processing. In order to complete crystallization and obtain the material suitable for a quantitative XRD phase analysis (Salak et al., 2013; Carneiro et al., 2015) the formed MMO were heat-treated at higher temperature, namely at $1000^{\circ} \mathrm{C}$ for 6 h. Fig. 3 and Fig. 4 demonstrate the XRD patterns of the resulting products. It is seen that along with the diffraction reflections from $\mathrm{MgO}$ and $\mathrm{CeO}_{2}$, the peaks attributed to the cubic spinel $\mathrm{MgAl}_{2} \mathrm{O}_{4}$ phase are present. The $\mathrm{Mg} /(\mathrm{Al}+\mathrm{Ce})$ molar ratios were estimated from the Rietveld analysis of the XRD data to be $3.22 \pm 0.15$ and $2.92 \pm 0.11$ for the MMO obtained from LDHs prepared by co-precipitation method and for the MMO from the sol-gel derived powders, respectively.

The ability of MMO to (re)form the LDH structure in water or water solutions was tested. The XRD patterns of the LDH samples formed as a result of hydration of the MMO obtained via coprecipitation and sol-gel methods are shown in Fig. 5 and 6, respectively.

The XRD patterns of the $\mathrm{Mg} / \mathrm{Al}$ samples (cerium free) synthesized by co-precipitation, calcined and then immersed in water (Fig. 5) indicate a complete transformation of mixed-metal oxides into an LDH phase. Thus, the reconstruction of layered structure of LDH initially prepared by coprecipitation method occurs in water. The calcined LDHs with a non-zero cerium content demonstrate, however, a less complete regeneration: reflections of the $\mathrm{CeO}_{2}$ phase are observed in the respective XRD patterns. Besides, it is clearly seen that the considerable amount of the amorphous part of the MMO product which contribute to a very broad peak of the XRD background remains uncrystallised.

The samples obtained by rehydration of the sol-gel derived samples show the typical LDH structure (Fig. 6), although no traces of an LDH phase has been detected at any stage of the sol-gel processing. Heat treatment of the sol-gels resulted in high crystalline MMO powders, which were hydroxylated in aqueous media providing well-crystallized LDH phase. According to the XRD patterns presented in Fig. 6, the mixed-metal oxides transformed fully to layered double hydroxides. Interestingly, the formation of LDH from the sol-gel derived powders does not depend on the Ce concentration in the samples. The XRD patterns of the reconstructed (hydroxylated) MMO powders demonstrate the sharp diffraction lines associated with an LDH crystalline phase only. No other crystalline phases have been detected. The (110) reflections of the LDHs are regularly shifted to a lower $2 \theta$ range as the cerium content is increased. Actually, the term "reconstruction" we use is not 
fully correct in the case of LDHs obtained from the sol-gel derived samples. In fact, this is a novel synthesis approach for the fabrication of LDHs, which is based on an aqueous sol-gel processing route.

The basal spacing (which are the distance between the adjacent hydroxide layers) and the lattice parameters of the LDH samples prepared by two different methods are listed in Table 1. The lattice parameter $a$ reflects an average cation-cation distance and can be calculated as $a=2 d_{(110)}$ from the interplanar distance corresponded to the (110) reflections in the brucite-like layers. Parameter $a$ is a function of both size and ratio of cations $\mathrm{M}^{2+}$ and $\mathrm{M}^{3+}$. Parameter $c$ depends mainly on size, charge and orientation of the intercalated species: anions and water molecules (Salak et al, 2014). In order to minimize the experimental error caused by the $2 \theta$ scale shift, $c$-parameter is usually calculated using the interplanar distances of at least two basal reflections: typically, (003) and (006), as $c=3 / 2$ $\left[d_{(003)}+2 d_{(006)}\right]$. The obtained crystallographic data (Table 1) suggest that the observed variation in the lattice parameters of the $\mathrm{Mg} / \mathrm{Al} / \mathrm{Ce} \mathrm{LDHs}$ are caused by substitution of aluminium by cerium in the host layers.

Because of the relatively large ionic radius of $\mathrm{Ce}^{3+}(1.01 \AA)$, substitution of $\mathrm{Al}^{3+}(0.53 \AA)$ by $\mathrm{Ce}^{3+}$ is expected to lead to an expansion of the cation-cation distance in the brucite-like layers (Shannon, 1976). Therefore, as a result of the aluminium-to-cerium substitution, the $a$-parameter grows. Besides, the $c$-parameter increases as well, since because of such a substitution the layers become thicker. The effect of increase of both lattice parameters induced by this isovalent Al-to-Ce substitution is qualitatively the same as that in the case of an increase of the $\mathrm{Mg} / \mathrm{Al}$ cation ratio since $\mathrm{Mg}^{2+}$ is bigger than $\mathrm{Al}^{3+}$. Dependences of lattice parameters of the carbonate-intercalated $\mathrm{Mg} / \mathrm{Al} \mathrm{LDHs}$ on the $\mathrm{Mg} / \mathrm{Al}$ ratio have been reported (Newman and Jones 2001). It has been shown that when the ratio is increased from 1:1 to 3.5:1, the lattice parameters grow from about 3.02 to $3.07 \AA$ ( $a$-parameter) and from about 22.6 to $23.7 \AA$ (c-parameter). In this work, the $\mathrm{Mg} / \mathrm{Al} / \mathrm{Ce}$ LDHs prepared by co-precipitation were most likely intercalated with $\mathrm{CO}_{3}{ }^{2-}$, as the synthesis was conducted in a $\mathrm{NaHCO}_{3}$ solution (see Experimental). As regards of the $\mathrm{Mg} / \mathrm{Al} / \mathrm{Ce}$ layered double hydroxides formed via hydroxylation of the sol-gel derived MMO, these LDHs can be intercalated with $\mathrm{OH}^{-}$and $\mathrm{CO}_{3}{ }^{2-}$, because the water used for the rehydration procedure was not specially decarbonized. Indeed, the presence of carbonate in the LDH samples prepared using either coprecipitation or via sol-gel method was confirmed by FT-IR study. A spectral band at about 1360 $\mathrm{cm}^{-1}$ associated with $v_{3}^{\prime}$ vibration of $\mathrm{CO}_{3}{ }^{2-}$ was detected in the samples regardless of the preparation method used (Fig. S1 in Supplementary Material). At the same time, the presence of intercalated 
$\mathrm{OH}^{-}$cannot be unambiguously confirmed nor discarded by FT-IR, since one can hardly distinguish between the intercalated hydroxyl groups and those in the brucite-like layers.

In terms of the most compact (flat-laying) orientation, the anions $\mathrm{OH}^{-}$and $\mathrm{CO}_{3}{ }^{2-}$ give the same height of the interlayer gallery, which is equal to the double van der Waals radius of oxygen (Salak et al., 2014). Therefore, the values reported by Newman and Jones can be used as references for our LDHs. It is seen from Table 1 that the obtained lattice parameters of the Ce-substituted $\mathrm{Mg}_{3} \mathrm{Al}$ LDHs are above the aforementioned ranges. The obtained values of both $a$ - and $c$-parameters cannot be associated with any deviation in the $\mathrm{Mg} / \mathrm{Al}$ ratio and certainly indicate the gradual substitution of aluminium by cerium in the brucite-like layers.

The Al-to-Ce isomorphic substitution rate in the obtained $\mathrm{Mg} / \mathrm{Al} / \mathrm{Ce} \mathrm{LDHs}$ was estimated using the expression based on that proposed by Richardson (Richardson, 2012) for case of substitution by two different trivalent cations:

$$
a_{L D H}=a_{M g(O H)_{2}}-\frac{1}{2} \sin \left(\frac{\alpha}{2}\right)\left[r\left(M^{2+}\right)-(1-x) r\left(A l^{3+}\right)-x r\left(C e^{3+}\right)\right]
$$

Values of the parameter $a$ for $\mathrm{Mg}(\mathrm{OH})_{2}$ and the angle $\alpha$ were taken from the paper by Brindley and Kao (Brindley and Kao, 1984) and the Shannon's ionic radii (Shannon, 1976) were used. The calculated $a$-parameter value for the ideal $\mathrm{Mg} / \mathrm{Al} / \mathrm{Ce} 10 \mathrm{~mol} . \% \mathrm{LDH}(3.089 \AA)$ was compared with the experimentally obtained values. It was found that the real amount of cerium that substituted aluminium in the $\mathrm{Mg} / \mathrm{Al} / \mathrm{Ce} 10 \mathrm{~mol} \% \mathrm{LDHs}$ is about 8 and $6 \mathrm{~mol} . \%$ for the samples prepared by co-precipitation and through sol-gel, respectively.

Based on the obtained results, the methods of fabrication of the $\mathrm{Mg} / \mathrm{Al} / \mathrm{Ce} \mathrm{LDH}$ applied in this work can be compared. As seen from Fig. 1 and Fig. 6, both the co-precipitation method and the sol-gel method provide a gradual Al-to-Ce substitution, although some amount of Ce does not incorporate into the LDH layers and crystallize as cerium oxide. It follows from a comparison of the lattice parameters of LDHs of the same nominal composition but prepared by different methods that when the nominal composition is $5-10 \mathrm{~mol} . \%$ of $\mathrm{Ce}$, the sol-gel method of the $\mathrm{LDH}$ preparation provides higher substitution rates. At the same time, in the case of small-rate substitutions, both methods give similar results. Our idea was the following: if we prove that at least $5 \mathrm{~mol} \%$ of $\mathrm{Al}$ can be substituted by $\mathrm{Ce}$, it guarantees that smaller-rate substitutions are successful a fortiori. In the study of the luminescence properties, where LDHs with the small substitution rates $(1 \mathrm{~mol} . \%$ and less) were used, we considered the LDHs of the same nominal composition but prepared by different methods as chemically equal.

The results of the thermogravimetric analysis of the LDHs synthesised by two different methods are shown in Figs. 7 and 8. The initial mass loss was observed in the temperature ranges of 30- 
$150^{\circ} \mathrm{C}(\sim 18 \%)$ and $30-200^{\circ} \mathrm{C}(\sim 17 \%)$ for the $\mathrm{Mg} / \mathrm{Al} / \mathrm{Ce} 10 \mathrm{~mol} \% \mathrm{LDH}$ prepared by co-precipitation and sol-gel methods, respectively. Some decrease in mass occurs even below $100^{\circ} \mathrm{C}$ because of evolution of the adsorbed water. (Tang et al., 2002). The main decomposition of $\mathrm{Mg} / \mathrm{Al} / \mathrm{Ce} 10$ mol\% sample prepared by co-precipitation method occurs via two steps in the temperature ranges of $290-350^{\circ} \mathrm{C}$ and $350-600^{\circ} \mathrm{C}$. These thermal behaviours result from the loss of the coordinated water and the intercalated anions (in the lower temperature range) and dehydroxylation of the layers followed by collapse of the layered structure (in the higher temperature range). However, the main decomposition of $\mathrm{Mg} / \mathrm{Al} / \mathrm{Ce} 10 \mathrm{~mol} \%$ sample prepared by sol-gel method occurs in one step by monotonic weight decrease in the temperature range of $200-600^{\circ} \mathrm{C}$.

The luminescent properties of the obtained LDHs were also investigated. The luminescence wavelengths of $\mathrm{Ce}^{3+}$ ions change widely from near UV to the red range depending on the nature of the host lattices (Kompe et al., 2003; Li et al., 2003). The emission spectra of $\mathrm{Mg} / \mathrm{Al} / \mathrm{Ce}$ samples fabricated by co-precipitation method is shown in Fig. 9. All powders were excited at $340 \mathrm{~nm}$ for taking the emission spectra. The major emission lines are peaked at $\sim 370-390 \mathrm{~nm}$. The broad bands are attributed to $[\mathrm{Xe}] 5 \mathrm{~d}^{1}-[\mathrm{Xe}] 5 \mathrm{f}^{1}$ transition of $\mathrm{Ce}^{3+}$ ions (Katelnikovas et al., 2010). Surprisingly, the highest intensity of ${ }^{5} \mathrm{D}_{0} \rightarrow{ }^{7} \mathrm{~F}_{2}$ transition was observed for $\mathrm{Mg} / \mathrm{Al} / \mathrm{Ce} 0.05 \mathrm{~mol} \%$ specimen. It turned out that emission intensity decreases with increasing concentration of $\mathrm{Ce}^{3+}$ up to $1 \mathrm{~mol} \%$. The emission maximum was also slightly shifted towards a red spectral region when more $\mathrm{Ce}^{3+}$ was introduced into the host lattice. This is in a good agreement with the results obtained in the $\mathrm{Ce}^{3+}$ doped garnet-type phosphors. In the emission spectra of the sol-gel derived $\mathrm{Mg} / \mathrm{Al} / \mathrm{Ce}$ samples (Fig. 10), the bands are broader and more intensive. Moreover, the maximum of the emission of the LDHs synthesized using sol-gel technique is red shifted $(390-430 \mathrm{~nm})$ in comparison with the LDH phosphors prepared by co-precipitation method. Fig. 9 also shows the emission spectra of the $\mathrm{Mg} / \mathrm{Al} / \mathrm{Ce}$ LDHs synthesized by co-precipitation method, calcined and then reconstructed. It is interesting to note the light output is much stronger in the reconstructed cerium-doped LDHs. Moreover, the red-shift of the emission maximum of the reconstructed $\mathrm{Mg} / \mathrm{Al} / \mathrm{Ce}$ sample is also evident. On the other hand, the highest intensity of ${ }^{5} \mathrm{D}_{0} \rightarrow{ }^{7} \mathrm{~F}_{2}$ transition still is determined for $\mathrm{Mg} / \mathrm{Al} / \mathrm{Ce} 0.05 \mathrm{~mol} \%$ specimen. With further increasing cerium content up to $1 \%$ the concentration quenching was observed (Devaraju et al., 2009).

The morphology of the synthesized $\mathrm{Mg} / \mathrm{Al}$ and $\mathrm{Mg} / \mathrm{Al} / \mathrm{Ce}$ samples was examined using scanning electron microscopy. The characteristic feature of synthesized LDH should be formation of platelike particles with hexagonal shape (Costa et al., 2008; Xu et al., 2010). The rehydration results in (re)generation of the metal hydroxide sheets and the plate-like geometry of the primary particles. 
The SEM micrographs represent the cerium-free $\mathrm{Mg} / \mathrm{Al} \mathrm{LDH}$ powders synthesized by coprecipitation method (Fig. 11). The typical LDH microstructure is evident from this SEM micrograph. The surface is composed of the agglomerated small plate-like particles of 50-100 nm in diameter. After calcination of $\mathrm{Mg} / \mathrm{Al} \mathrm{LDH}$ at $650^{\circ} \mathrm{C}$, the network of spherical nanoparticles (50 to $100 \mathrm{~nm}$ ) have formed. Rehydration of these nanopowders results in formation of plate-like particles with hexagonal shape (Fig. 11c). However, after such a reconstruction, the average particle size of the LDHs increases to $\sim 100-150 \mathrm{~nm}$. The surface morphology of the $\mathrm{Ce}^{3+}$-substituted samples is very similar for all the specimens independent of the substitution rate. The representative SEM micrographs (Fig. 12) of the $\mathrm{Mg} / \mathrm{Al} / \mathrm{Ce} 1 \mathrm{~mol} \%$ sample synthesized by co-precipitation method, calcined and then reconstructed show small fibrous plate-like particles that are aggregated as in the case of a cerium-free LDH sample. The SEM micrographs of the $\mathrm{Mg} / \mathrm{Al} / \mathrm{Ce} 1 \mathrm{~mol} \%$ and $\mathrm{Mg} / \mathrm{Al} / \mathrm{Ce}$ 10 mol\% LDHs fabricated by sol-gel method followed by hydration are shown in Fig. 12. It is seen that the sol-gel derived $\mathrm{Mg} / \mathrm{Al} / \mathrm{Ce} \mathrm{LDHs}$ consist of the larger hexagonally shaped particles varying in size from approximately 150 to $200 \mathrm{~nm}$. The good connectivity between the grains is also observed. These nanograins show tendency to form larger agglomerates. On the whole, nanocrystalline nature of powders with the narrow size distribution of crystallites is observed for all the obtained LDH samples.

The luminescence properties are expected to depend on the closest coordination of $\mathrm{Ce}$ in the layer and hardly on the interlayer distance. The main difference between the LDHs prepared using either co-precipitation method or sol-gel-method is in size and regularity of the crystallites. It is known that the LDH crystallites obtained as a result of (re)hydration of the calcined powders are more irregular than those obtained by co-precipitation. Therefore we consider that the observed differences in the luminescence properties are caused by differences in morphology of the LDHs.

\section{Conclusions}

The $\mathrm{Mg} / \mathrm{Al}$ layered double hydroxides (LDHs) were successfully synthesized by co-precipitation method and using sol-gel preparation technique. To the best our knowledge the latter was successfully applied for production of LDHs for the first time. In this novel aqueous sol-gel processing route, the LDHs were obtained as a result of decomposition (calcination) of the precursor gels at $650^{\circ} \mathrm{C}$ followed by rehydration of the intermediate crystalline MMO powders in water. The same synthesis methods were successfully applied for production of cerium-substituted LDHs $(\mathrm{Mg} / \mathrm{Al} / \mathrm{Ce})$ with the substitution rate from 0.05 to $10 \mathrm{~mol} \%$. It was found that in case of the $\mathrm{Mg} / \mathrm{Al} / \mathrm{Ce} \mathrm{LDHs}$ prepared by co-precipitation followed by calcination, the regeneration rate 
decreases with increase of cerium content, while the conversion of the rehydrated sol-gel derived MMO into LDH does not depend on the concentration of cerium and is close to $100 \%$. The proposed sol-gel synthesis route for LDHs has some benefits over conventional method such as simplicity, high homogeneity of the end products, effectiveness, suitability to study substitution effects for different multinary metal systems and cost efficiency.

The luminescent properties of the obtained LDHs were also investigated. The major emission lines attributed to the $[\mathrm{Xe}] 5 \mathrm{~d}^{1}-[\mathrm{Xe}] 5 \mathrm{f}^{1}$ transition of $\mathrm{Ce}^{3+}$ ions were peaked at $\sim 370-390 \mathrm{~nm}$ and 390 $430 \mathrm{~nm}$ for the $\mathrm{Mg} / \mathrm{Al} / \mathrm{Ce}$ samples fabricated by co-precipitation and by sol-gel methods, respectively. The emission bands were broader, more intensive and red-shifted in the case of the sol-gel derived LDHs.

The typical LDH microstructure was observed in all the obtained samples. The surfaces of the LDHs prepared by co-precipitation were composed of agglomerated small plate-like particles of 50$100 \mathrm{~nm}$ in diameter. After calcination followed by reconstruction (rehydration), the particle size of obtained LDH was observed to increase to 100-150 nm. Even larger particles formed in case of the LDHs prepared by hydration from the sol-gel derived MMO powders.

Luminescence properties of cerium doped LDHs were found to depend on the morphology of the host lattice. The observed compositional behaviours of lattice parameters and the luminescence characteristics indicate the successful isomorphic incorporation of $\mathrm{Ce}^{3+}$ into the brucite-like layers of the $\mathrm{Mg}_{3} \mathrm{Al}_{1-x} \mathrm{Ce}_{x}$ LDHs at least when $x \leq 0.01$.

\section{Acknowledgements}

The work has been done in frame of the project TUMOCS. This project has received funding from the European Union's Horizon 2020 research and innovation programme under the Marie Skłodowska-Curie grant agreement No 645660. The financial support of P2020 COMPETE and FCT-Portugal through project POCI-01-0145-FEDER-016686 - PTDC/CTM-NAN/2418/2014 (NANOCONCOR) is also acknowledged.

\section{References}

Alvarez, M.G., Chimentao, R.J., Barrabes, N., Fottinger, K., Gispert-Guirado, F., Kleymenov, E., Tichit, D., Medina, F., 2013. Structure evolution of layered double hydroxides activated by induced reconstruction. Appl. Clay. Sci. 83-84, 1-11. 
Bi, X., Zhang, H., Dou, L., 2014. Layered Double Hydroxide-based nanocarriers for drug delivery. Pharmaceutics. 6, 298-332.

Binnemans, K., 2009. Lanthanide-Based Luminescent Hybrid Materials. Chem. Rev.109, 42834374.

Brindley, G.W., Kao, C.C., 1984. Structural and IR relations among brucite-like divalent metal hydroxides. Phys. Chem. Minerals 10, 187-191.

Carneiro, J., Caetano, A.F., Kuznetsova, A., Maia, F., Salak, A.N., Tedim, J., Scharnagl, N., Zheludkevich, M.L., Ferreira, M.G.S., 2015. Polyelectrolyte-modified Layered double hydroxide nanocontainers as vehicles for combined inhibitors. RSC Advances 5, 39916-39929.

Cosano, D., Esquinas, C., Jimenez-Sanchidrian, C., Ruiz, J.R., 2016, Use of Raman spectroscopy to assess the efficiency of MgAl mixed oxides in removing cyanide from aqueous solutions. Appl. Surf. Sci. 364, 428-433.

Costa, F., Leuteritz, A., Wagenknecht, U., Jehnichen, D., Häußler, L., Heinrich, G., 2008. Intercalation of $\mathrm{Mg}-\mathrm{Al}$ layered double hydroxide by anionic surfactants: preparation and characterization. Appl. Clay. Sci. 38, 153-164.

Devaraju, M.K., Yin, S., Sato, T., 2009. $\mathrm{Tm}^{3+}$ doped $\mathrm{Y}_{2} \mathrm{O}_{3}$ Nanocrystals: Rapid Hydrothermal Synthesis and Luminescence. Eur. J. Inorg. Chem. 29-30, 4441-4445.

Domínguez, M., Pérez-Bernal, M.E., Ruano-Casero, R.J., Barriga, C., Rives, V., Ferreira, R.A.S., Carlos, L.D., Rocha, J., 2011. Multiwavelength luminescence in lanthanide-doped hydrocalumite and mayenite. Chem. Mater 23, 1993-2004.

Gao, X.R., Lei, L.X., Kang, L.W., Wang, Y.Q., Lian, Y.W., Jiang, K.L., 2014. Synthesis, characterization and optical properties of a red organic-inorganic phosphor based on terephthalate intercalated $\mathrm{Zn} / \mathrm{Al} / \mathrm{Eu}$ layered double hydroxide. J. All. Compd. 585, 703-707.

Gunawan, P., Xu, R., 2009. Lanthanide-doped Layered Double Hydroxides intercalated with sensitizing anions: efficient energy transfer between host and guest layers. J. Phys. Chem. C. $113,17206-17214$.

Hu Z.; Chen G, 2014. Novel nanocomposite hydrogels consisting of layered double hydroxide with ultrahigh tensibility and hierarchical porous structure at low inorganic content. Adv. Mater. 26, $5950-5956$.

Jaubertie, C., Holgado, M.J., San Román, M.S., Rives, V., 2006. Molecular dynamics simulation of the energetics and structure of Layered Double Hydroxides intercalated with carboxylic acids. Chem. Mater. 18, 3114-3121. 
Jayaraj, M.K., Vallabhan, 1991. CPG AC Thin film electroluminescent devices with rare earth doped ZnS. Electrochem. Soc. 138, 512-515.

Katelnikovas, A., Sakirzanovas, S., Dutczak, D., Plewa, J., Enseling, D, Winkler, H., Kareiva, A., Jüstel, T., 2013. Synthesis and optical properties of yellow emitting garnet phosphors for pcLEDs. J. Lumin. 136, 17-25.

Katelnikovas, A., Plewa, J., Sakirzanovas, S., Dutczak, D., Enseling, D., Baur, F., Winkler, H., Kareiva, A., Jüstel, T., 2012. Synthesis and optical properties of green emitting garnet phosphors for phosphor-converted light emitting diode. J. Mater. Chem. 22, 22126-22134.

Katelnikovas, A., Plewa, J., Dutczak, D., Möller S, Enseling, D., Winkler, H., Kareiva, A., Jüstel, T., 2012. Synthesis and optical properties of green emitting garnet phosphors for phosphorconverted light emitting diodes. Opt. Mater. 34, 1195-1201.

Katelnikovas, A., Jurkevicius, J., Kazlauskas, K., Vitta, P., Jüstel, T., Kareiva, A., Zukauskas, A., Tamulaitis, G., 2011. Efficient Cerium-Based Sol-Gel Derived Phosphors in Different Garnet Matrices for Light-Emitting Diodes. J. All. Compd. 509, 6247-6251.

Katelnikovas, A., Bareika, T., Vitta, P., Justel, T., Winkler, H., Kareiva, A., Zukauskas, A., Tamulaitis, G., 2010. Warm-White Light Emitting Diodes. Opt. Mater. 32, 1261-1265.

Katelnikovas, A., Justel, T., Uhlich, D., Jorgensen, J.E., Sakirzanovas, S., Kareiva, A., 2008. Caracterization of cerium-doped ytrium aluminium garnet nanopowders synthesised via sol-gel process. Chem. Eng. Comm. 195, 758-769.

Katelnikovas, A., Vitta, P., Pobedinskas, P., Tamulaitis, G., Zukauskas, A., Jørgensen, J.E., Kareiva, A., 2007. Photoluminescence in sol-gel-derived YAG: Ce phosphors. J. Cryst. Growth. $304,361-368$.

Klemkaite-Ramanauske, K., Zilinskas, A., Taraskevicius, R., Khinsky, A., Kareiva, A., 2014. Preparation of $\mathrm{Mg} / \mathrm{Al}$ layered double hydroxide (LDH) with structurally embedded molybdate ions and application as a catalyst for the synthesis of 2-adamantylidene(phenyl)amine schiff Base. Polyhedron. 68, 340-345.

Klemkaite, K., Prosycevas, I., Taraskevicius, R., Khinsky, A., Kareiva, A., 2011. Synthesis and characterization of layered double hydroxides with different cations ( $\mathrm{Mg}, \mathrm{Co}, \mathrm{Ni}, \mathrm{Al})$, decomposition and reformation of mixed metal oxides to layered structures. Centr. Eur. J. Chem. 9, $275-282$.

Klemkaite, K., Khinsky, A., Kareiva, A., 2011. Reconstitution effect of Mg/Ni/Al Layered Double Hydroxide. Mater. Lett. 65, 388-391. 
Kömpe, K., Borchert, H., Storz, J., Lobo, A., Adam, S., Möller, T., Haase, M., 2003. Nanoparticles with 70 \% Photoluminescence Quantum Yield. Angew. Chem. Int. Ed. 42, 5513-5516.

Kuwahara, Y., Tamagawa, S., Fujitani, T., Yamashita, H., 2016. Removal of phosphate from aqueous solution using Layered Double Hydroxide prepared from waste iron-making slag. Bull. Chem. Soc. Jpn. 89, 472-480.

Lu, P., Liang, S., Qiu, L., Gao, Y.S., Wang, Q., 2016. Layered double hydroxide/graphene oxide hybrid incorporated polysulfone substrate for thin-film nanocomposite forward osmosis membranes. J. Membr. Sci. 504, 196-205.

Li, H.J., Su, X.Y., Bai. C.H., Xu, Y.Q., Pei, Z.C., Sun, S.G., 2016. Graphene based sensor for environmental monitoring of $\mathrm{NO}_{2}$. Sensors. Actuat B-Chemical. 225, 109-114.

Liu, L.L., Xia, D., Liu, W.S., Tang, Y., 2013. Initial theoretical evaluation of pore structure for metal-organic frameworks. Chin. J. Inorg. Chem. 29, 1663-1667.

Li, F.Y., Xia, Z.Q., Yang, S.P., Gao, S.Y., 2004. Synthesis of single-phase nanocrystalline garnet phosphor derived from gel-network-coprecipitation. J. Mater. Sci. 39, 4711-4713.

Liu J.; Chen G.; Yang J., 2008. Preparation and characterization of poly (vinyl chloride)/layered double hydroxide nanocomposites with enhanced thermal stability. Polymer. 49, 3923-3927.

Mascolo, G., Mascolo, M.C., 2015. On the synthesis of layered double hydroxides (LDH) by reconstruction, method based on the "memory effect". Microporous and Mesoporous Materials. $214,246-248$.

Maqbool, M., Ahmad, I., Richardson, H.H., Kordesch, M.E., 2007. Direct ultraviolet excitation of an amorphous AIN: praseodymium phosphor by codoped $\mathrm{Gd}^{3+}$ cathodoluminescence. Appl. Phys. Lett. 91, 193511(1-3).

Maqbool, M., 2006. Luminescence from thulium and samarium doped amorphous AlN thin films deposited by RF magnetron sputtering and the effect of thermal activation on luminescence. Eur. Phys. J. Appl. Phys. 34, 31-34.

Misevicius. M., Scit, O., Grigoraviciute-Puroniene, I., Degutis, G., Bogdanoviciene, I., Kareiva, A., 2012. Synthesis, hydration and thermal stability of hydrates in strontium-aluminate cement. Ceram. Int. 38, 5915-5924.

Miyata, S., 1983. Anion-exchange properties of hydrotalcite-like compounds. Clays. Clay. Min. 31, 305-314.

Newman, S.P., Jones, W., 1998. Synthesis, characterization and applications of layered double hydroxides containing organic guests. New. J. Chem. 22, 105-115. 
Newman, S.P., Jones, W., 2001. Layered double hydroxides as templates for the formation of supramolecular structures. Supramolecular Organization and Materials Design, ed. W. Jones and C. N. R. Rao, Editors, 295-331, Cambridge University Press, Cambridge.

Okamoto, K., Yoshimi, T., Miura, S., 1988. TbOF complex centers in ZnS thin-film electroluminescent devices. Appl. Phys. Lett. 53, 678-680.

Posati, T., Costantino, F., Latterini, L., Nocchetti, M., Paolantoni, M., Tarpani, L., 2012. Hydrotalcite-like materials as precursors of catalysts to produce hydrogen from methanol. Inorg. Chem. 51, 13229-13236.

Richardson, I.G., 2012. The importance of proper crystal-chemical and geometrical reasoning demonstrated using layered single and double hydroxides. Acta Cryst. Sect. B 69, 150-162.

Rives, V., 2001. Layered Double Hydroxides: Present and Future: book. Nova. Science. Publishers., New York.

Salak A.N., Tedim J., Kuznetsova A.I., Ribeiro J.L., Vieira L.G., Zheludkevich M.L., Ferreira M.G.S., 2012. Comparative x-ray diffraction and infrared spectroscopy study of Zn-Al layered double hydroxides: vanadate vs nitrate, Chem. Phys. 397, 102-108.

Salak, A.N., Tedim, J., Kuznetsova, A.I., Vieira, L.G., Ribeiro, J.L., Zheludkevich, M.L., Ferreira, M.G.S., 2013. Thermal behavior of layered double hydroxide Zn-Al-pyrovanadate: composition, structure transformations, recovering ability. J. Phys. Chem. C 117, $4152-$ 4157.

Salak, A.N., Lisenkov, A.D., Zheludkevich, M.L., Ferreira, M.G.S., 2014. Carbonate-free Zn-Al (1:1) layered double hydroxide film directly grown on zinc-aluminum alloy coating. ECS Electrochem. Lett. 3, C9-C11.

Serdechnova, M., Salak, A.N., Barbosa, F.S., Vieira, D.E.L., Tedim, J., Zheludkevich, M.L., Ferreira, M.G.S., 2016. Interlayer intercalation and arrangement of 2mercaptobenzothiazolate and 1,2,3-benzotriazolate anions in layered double hydroxides: in situ X-ray diffraction study. J. Solid State Chem. 233, 158-165.

Shannon, R.D., 1976. Revised effective ionic radii and systematic studies of interatomic distances in halides and chalcogenides. Acta. Crystallogr. Sec. A 32, 751-767.

Skaudzius, R., Juestel, T., Kareiva, A., 2016. Study of $\mathrm{Eu}^{3+}$ and $\mathrm{Tm}^{3+}$ substitution effects in sol-gel fabricated calcium hydroxyapatite. Mater. Chem. Phys. 170, 229-238.

Stanulis, A., Katelnikovas, A., Enseling, D., Dutczak, D., Sakirzanovas, S., Van Bael, M., Hardy, A., Kareiva, A., Jüstel, T., 2014. Luminescence properties of $\mathrm{Sm}^{3+}$-doped alkaline earth orthostannates. Opt. Mater. 36, 1146-1152. 
Tamboli, A.H., Jadhav, AR., Chung, W.J., Kim, H., 2015. Catalyst for hydrogen production from sodium borohydride hydrolysis. Energy 93, 955-962.

Vargas, D.R.M., Oviedo, M.J., Lisboa, F.D., Wypych, F., Hirata, G.A., 2013. Phosphor dysprosium-doped Layered Double Hydroxides exchanged with different organic functional groups. J. Nanomater. Art. ID 730153, 1-8.

Vicente, P., Pérez-Bernal, M.E., Ruano-Casero, R.J., Ananias, D., Almeida Paz, F.A., Rocha, J., Rives, V., 2016. Luminescence properties of lanthanide-containing layered double hydroxides. Microporous and Mesoporous Materials 226, 209-220.

William, M. Y., Shionoya, S., Yamamoto, H., 2006. Fundamentals of Phosphors. CRC. Press. Inc, Ltd. Boca Raton. FL, 335.

Wu, J., Ren, Z.Y., Du, S.C., Kong, L.J., Liu, B.W., Xi, W., Zhu, J.Q., Fu, H.G., 2016. Dehydrated layered double hydroxides: Alcohothermal synthesis and oxygen evolution activity. Nano Res. 9, 713-725.

Xu, Z.P., Braterman, P.S., 2010. Synthesis, structure and morphology of organic layered double hydroxide (LDH) hybrids: Comparison between aliphatic anions and their oxygenated analogist. Appl. Clay. Sci. 48, 235-242.

Yang, W., Kim, Y., Liu, P., Sahimi, M., Tsotsis, T., 2002. A study by in situ technique of the thermal evolution of the structure of a $\mathrm{Mg}-\mathrm{Al}-\mathrm{CO}_{3}$ layered double hydroxide. Chem. Eng. Sci. 57, 2945-2953.

Zabiliute, A., Butkute, S., Zukauskas, A., Vitta P., Kareiva, A., 2014. Sol-gel synthesized far-red chromium-doped garnet phosphors for phosphor-conversion light-emitting diodes that meet the photomorphogenetic needs of plants. Appl. Optics. 53, 907-914.

Zhang, W.J., Li, Y.L., Fan, H.X., 2016. Lanthanide luminescence for biomedical analyses and imaging. Opt. Mater. 51, 78-83.

Zhang, Z., Chen, G.M., Liu, J.G., 2014. Tuneable photoluminescence of europium-doped layered double hydroxides intercalated by coumarin-3-carboxylate. RSC Adv. 4, 7991-7997.

Zhao, Y., Li, F., Zhang, R., Evans, D.G., Duan, X., 2002. Preparation of layered double-hydroxide nanomaterials with a uniform crystallite size using a new method involving separate nucleation and aging steps. Chem. Mater. 14, 4286-4291. 


\section{Highlights}

- $\mathrm{The} \mathrm{Mg} / \mathrm{Al} / \mathrm{Ce}$ layered double hydroxides (LDHs) synthesised using co-precipitation and sol-gel preparation technique.

- The rehydration of sol-gel derived LDH does not depend on the concentration of cerium used in the samples as was the case in the co-precipitation approach.

- The emission bands more intensive and red-shifted for the sol-gel derived specimens.

- $\quad \mathrm{The} \mathrm{Mg} / \mathrm{Al} / \mathrm{Ce}$ solids are homogeneous having small particle size distribution. 
Table 1. The basal spacings $(d)$ and lattice parameters $(a, c)$ of $\mathrm{Mg} / \mathrm{Al} \mathrm{LDH}$ and $\mathrm{Mg} / \mathrm{Al} / \mathrm{Ce} \mathrm{LDHs}$ synthesised by co-precipitation and sol-gel methods.

\begin{tabular}{lccccc}
\hline $\begin{array}{c}\text { The cation } \\
\text { composition }\end{array}$ & $\boldsymbol{d}_{(003)}(\boldsymbol{A})$ & $\boldsymbol{d}_{(006)}(\AA)$ & $\boldsymbol{d}_{(110)}(\AA)$ & $\boldsymbol{a}(\AA)$ & $\boldsymbol{c}(\AA)$ \\
\hline \multicolumn{5}{c}{ Co-precipitation method } \\
$\mathrm{Mg} / \mathrm{Al}$ & 7.9627 & 3.9482 & 1.5344 & 3.067 & 23.878 \\
$\mathrm{Mg} / \mathrm{Al} / \mathrm{Ce} 5 \mathrm{~mol} \%$ & 7.9463 & 3.9479 & 1.5347 & 3.068 & 23.828 \\
$\mathrm{Mg} / \mathrm{Al} / \mathrm{Ce} 7.5 \mathrm{~mol} \%$ & 7.9541 & 3.9510 & 1.5356 & 3.070 & 23.852 \\
$\mathrm{Mg} / \mathrm{Al} / \mathrm{Ce} 10 \mathrm{~mol} \%$ & 7.9634 & 3.9609 & 1.5376 & 3.074 & 23.880 \\
\hline & & Sol-gel method & & \\
$\mathrm{Mg} / \mathrm{Al}$ & 7.9181 & 3.9300 & 1.5346 & 3.068 & 23.744 \\
$\mathrm{Mg} / \mathrm{Al} / \mathrm{Ce} 5 \mathrm{~mol} \%$ & 7.9476 & 3.9483 & 1.5351 & 3.069 & 23.832 \\
$\mathrm{Mg} / \mathrm{Al} / \mathrm{Ce} 7.5 \mathrm{~mol} \%$ & 7.9683 & 3.9499 & 1.5376 & 3.074 & 23.894 \\
$\mathrm{Mg} / \mathrm{Al} / \mathrm{Ce} 10 \mathrm{~mol} \%$ & 8.1418 & 3.9897 & 1.5411 & 3.081 & 24.415 \\
\hline
\end{tabular}




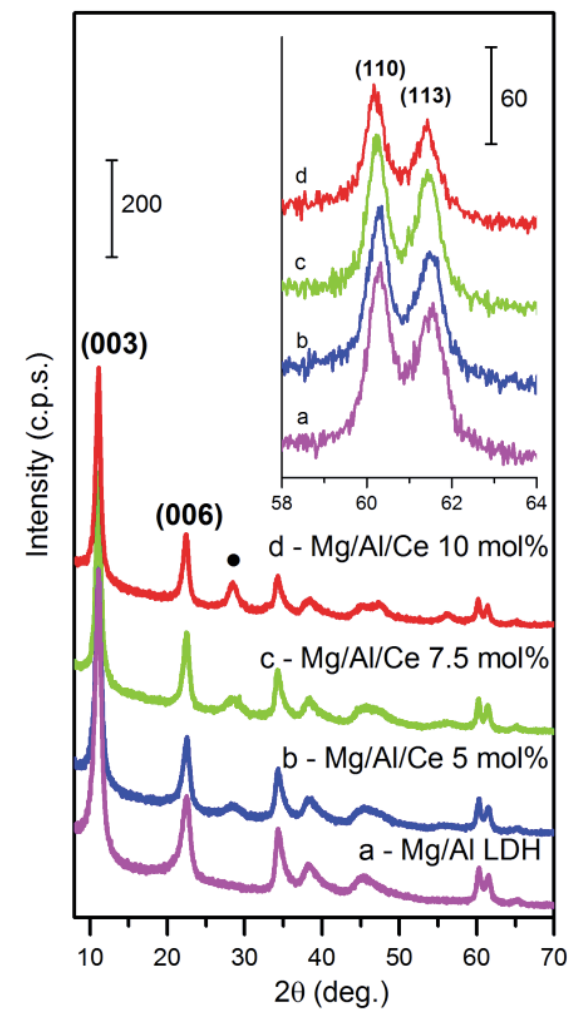

Fig. 1. XRD patterns of the $\mathrm{Mg} / \mathrm{Al} / \mathrm{Ce} \mathrm{LDHs}$ synthesized by co-precipitation method: (a) ceriumfree, (b) $5 \mathrm{~mol} \%$ of Ce, (c) $7.5 \mathrm{~mol} \%$ of Ce, (d) $10 \mathrm{~mol} \%$ of Ce. The basal reflection is indicated. Inset: the XRD patterns in the range of (110) and (113) diffraction reflections. The crystalline phase is marked: $\bullet-\mathrm{CeO}_{2}$ 


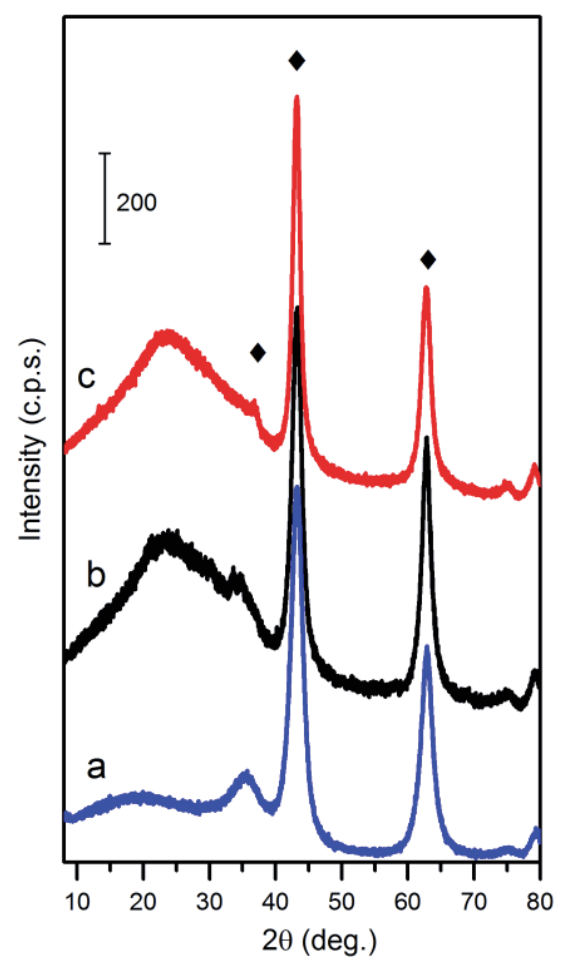

Fig. 2. XRD patterns of $\mathrm{Mg} / \mathrm{Al} \mathrm{LDH}$ calcined at $650^{\circ} \mathrm{C}$ : (a) commercial Pural MG63HT, (b) synthesized by co-precipitation and (c) sol-gel methods. The $\mathrm{MgO}$ phase is marked as 


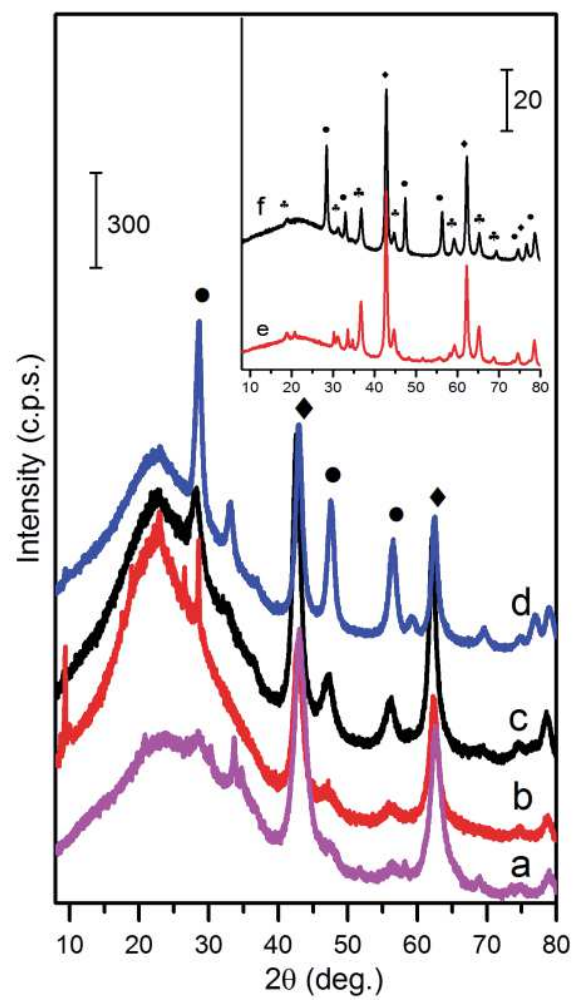

Fig. 3. XRD patterns of $\mathrm{Mg} / \mathrm{Al} / \mathrm{Ce} \mathrm{LDHs}$ synthesised by co-precipitation method and calcined at $650^{\circ} \mathrm{C}$ : (a) $1 \mathrm{~mol} \%$ of $\mathrm{Ce}$, (b) $5 \mathrm{~mol} \%$ of Ce, (c) $7.5 \mathrm{~mol} \%$ of Ce, (d) $10 \mathrm{~mol} \%$ of Ce. Calcined at $1000^{\circ} \mathrm{C}$ : (e) cerium-free; (f) $7.5 \mathrm{~mol} \%$ of Ce. The crystalline phases are marked: $-\mathrm{MgO} ; \bullet-\mathrm{CeO}_{2}$; \& $\mathrm{MgAl}_{2} \mathrm{O}_{4}$ 


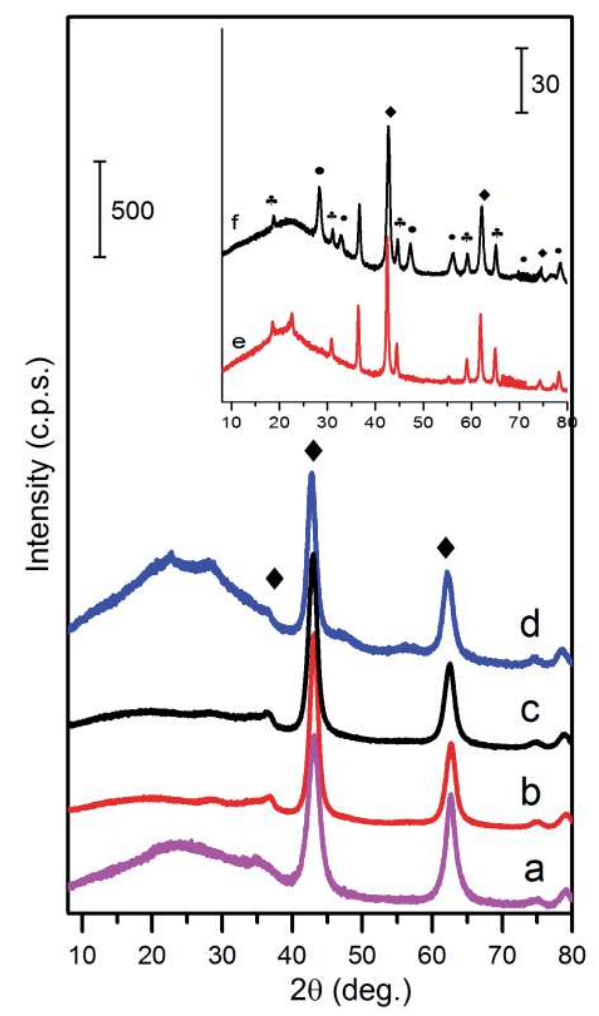

Fig. 4. XRD patterns of gels $\mathrm{Mg} / \mathrm{Al} / \mathrm{Ce} \mathrm{LDHs}$ calcined at 650: (a) $1 \mathrm{~mol} \%$ of Ce, (b) $5 \mathrm{~mol} \%$ of Ce, (c) $7.5 \mathrm{~mol} \%$ of Ce, (d) $10 \mathrm{~mol} \%$ of Ce. Calcined at $1000^{\circ} \mathrm{C}$ : (e) cerium-free, (f) $7.5 \mathrm{~mol} \%$ of Ce. The crystalline phases are marked: $-\mathrm{MgO} ; \bullet-\mathrm{CeO}_{2} ; \mathrm{MgAl}_{2} \mathrm{O}_{4}$ 


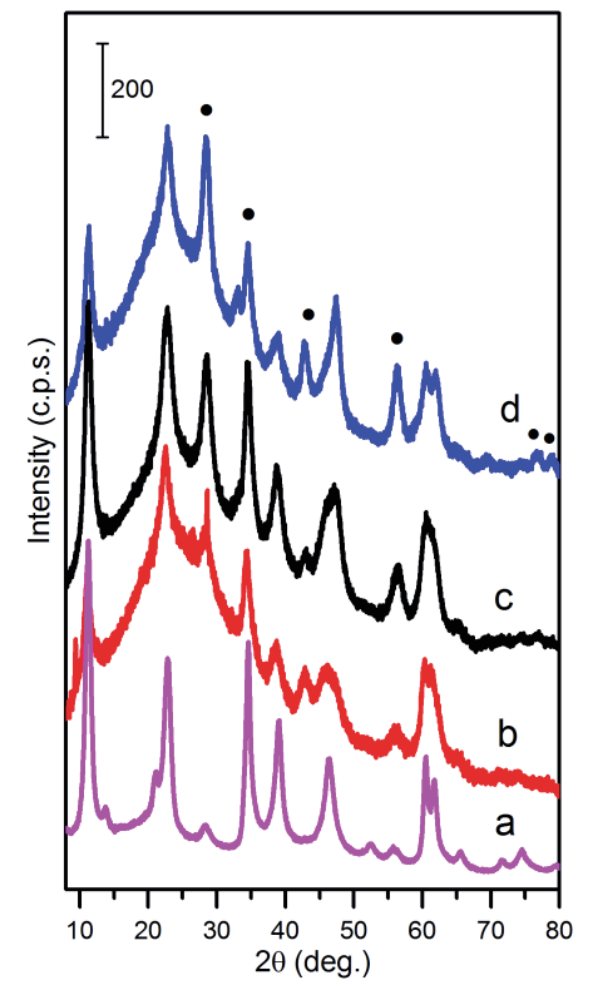

Fig. 5. XRD patterns of $\mathrm{Mg} / \mathrm{Al} / \mathrm{Ce} \mathrm{LDHs}$ synthesized by co-precipitation method and reconstructed: (a) $1 \mathrm{~mol} \%$ of Ce, (b) $5 \mathrm{~mol} \%$ of Ce, (c) $7.5 \mathrm{~mol} \%$ of Ce, (d) $10 \mathrm{~mol} \%$ of Ce; ${ }^{\cdot} \mathrm{CeO}_{2}$ 


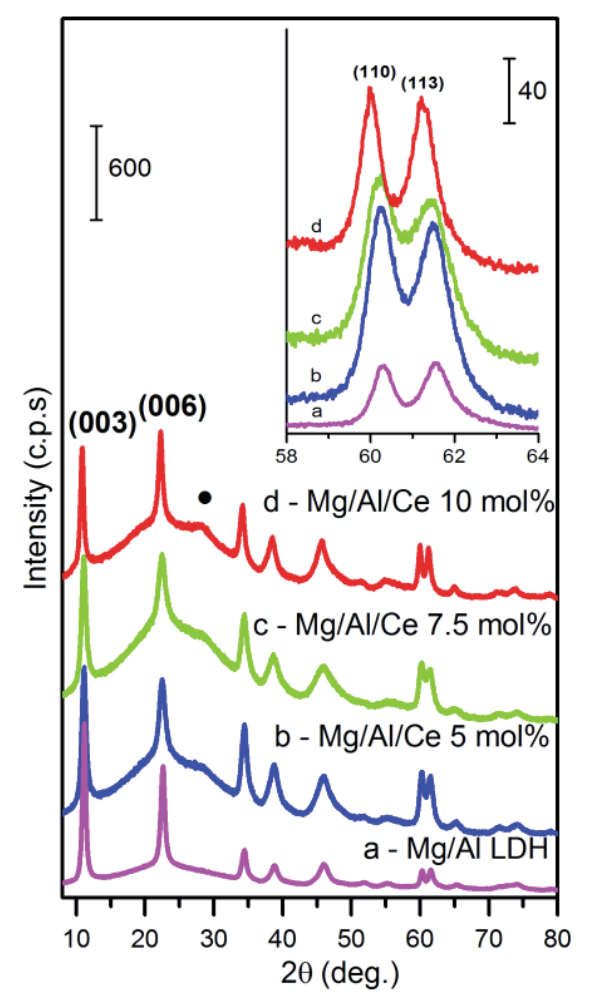

Fig. 6. XRD patterns of the $\mathrm{Mg} / \mathrm{Al} / \mathrm{Ce} \mathrm{LDHs}$ synthesized by sol-gel method using reconstruction approach: (a) cerium-free, (b) $5 \mathrm{~mol} \%$ of $\mathrm{Ce}$, (c) $7.5 \mathrm{~mol} \%$ of Ce, (d) $10 \mathrm{~mol} \%$ of Ce. The basal reflection is indicated. Inset: the XRD patterns in the range of (110) and (113) diffraction reflections. The crystalline phase is marked: $\bullet-\mathrm{CeO}_{2}$ 


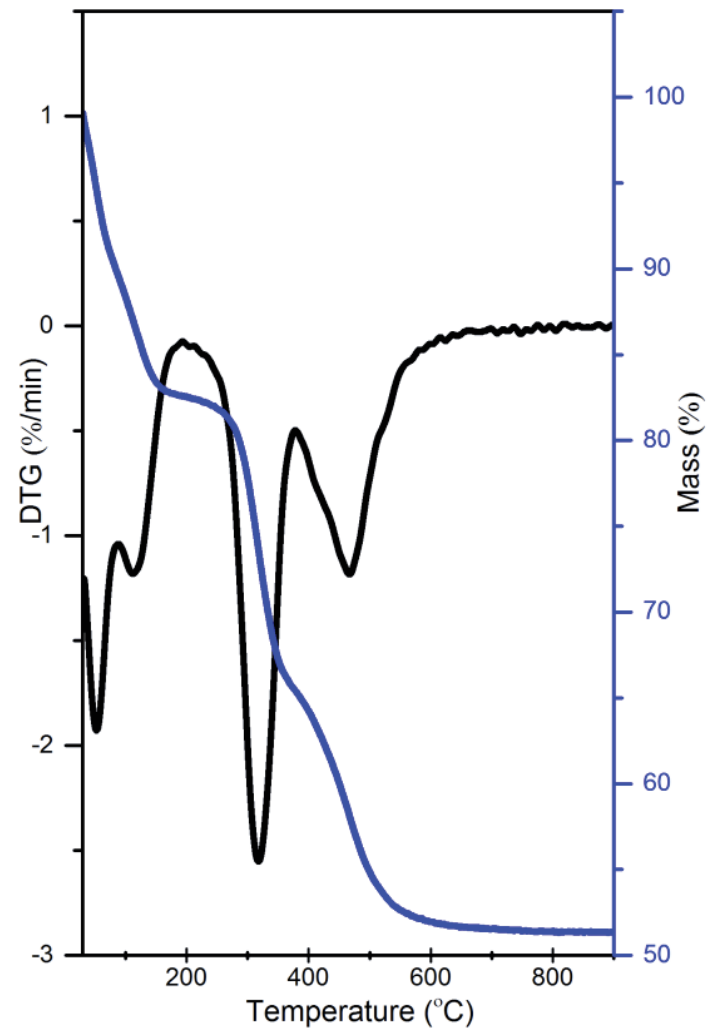

Fig. 7. TG-DTG curves recorded for the $\mathrm{Mg} / \mathrm{Al} / \mathrm{Ce} 10 \mathrm{~mol} \% \mathrm{LDH}$ sample synthesized by co-precipitation method 


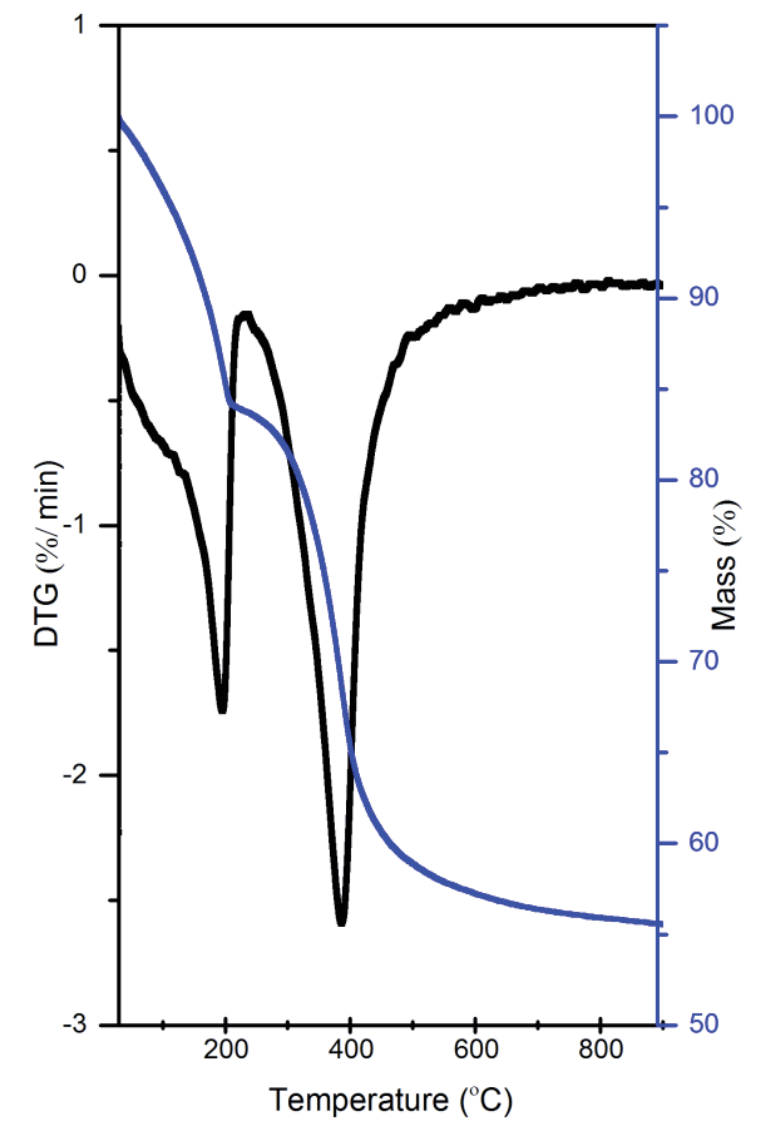

Fig. 8. TG-DTG curves recorded for the $\mathrm{Mg} / \mathrm{Al} / \mathrm{Ce} 10 \mathrm{~mol} \% \mathrm{LDH}$ sample synthesized by sol-gel method 


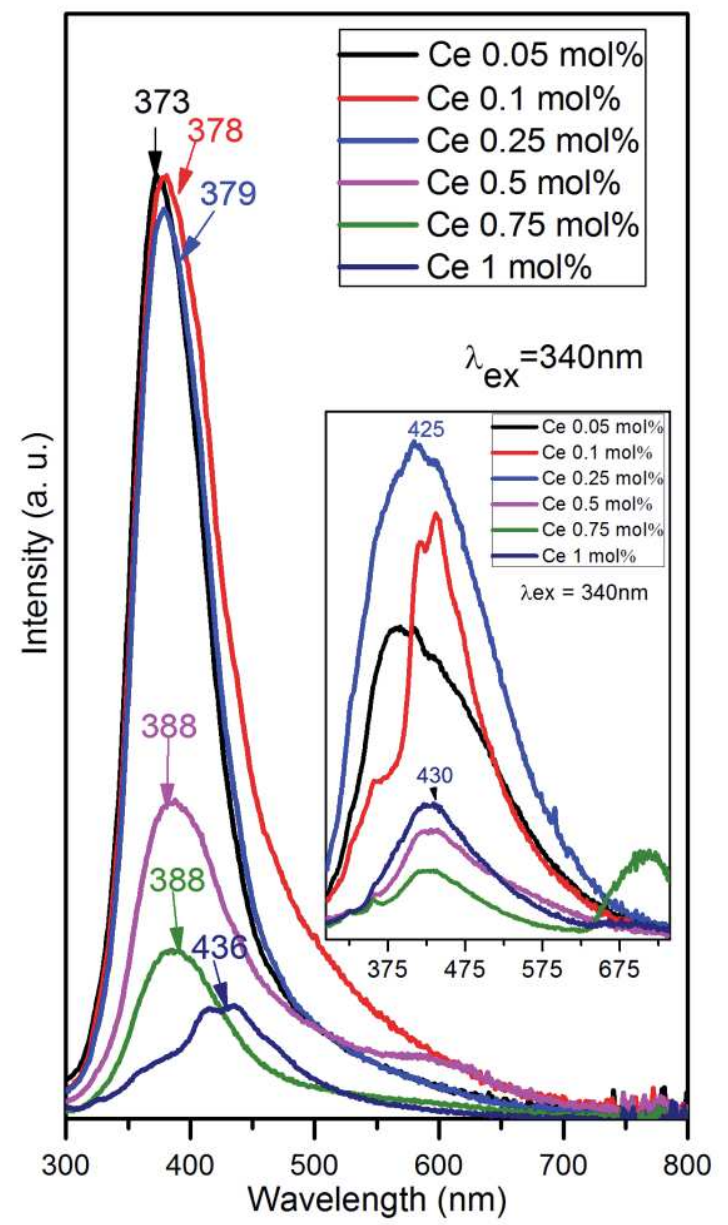

Fig. 9. Emission spectra of $\mathrm{Mg} / \mathrm{Al} / \mathrm{Ce} \mathrm{LDHs}$ synthesized by co-precipitation method and reduced view of reconstruction. 


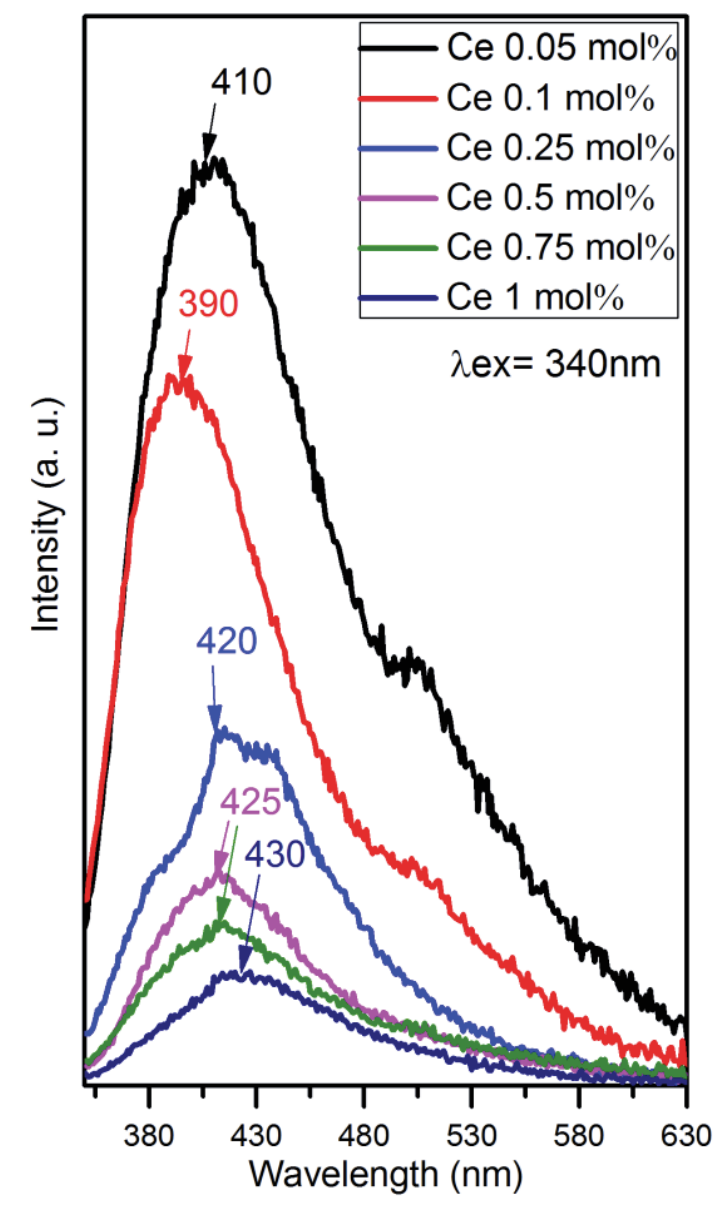

Fig. 10. Emission spectra of $\mathrm{Mg} / \mathrm{Al} / \mathrm{Ce} \mathrm{LDH}$ synthesized by sol-gel method 
Click here to download Figure: Figure11.docx
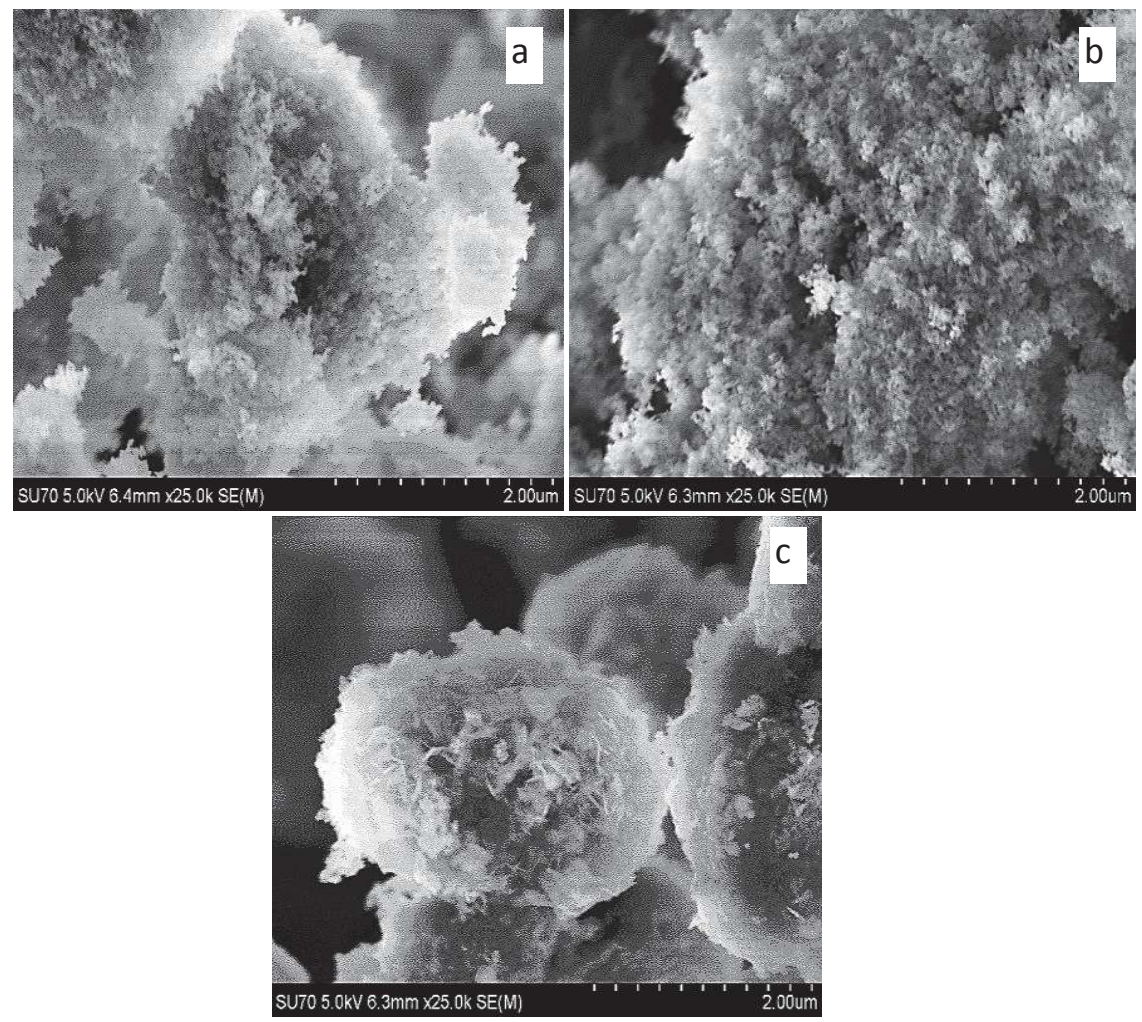

Fig. 11. SEM micrographs of a) Mg/Al LDH synthesized by co-precipitation method, b) Mg/Al $\mathrm{LDH}$ calcined at $650{ }^{\circ} \mathrm{C}$ and c) reconstructed $\mathrm{Mg} / \mathrm{Al} \mathrm{LDH}$ 


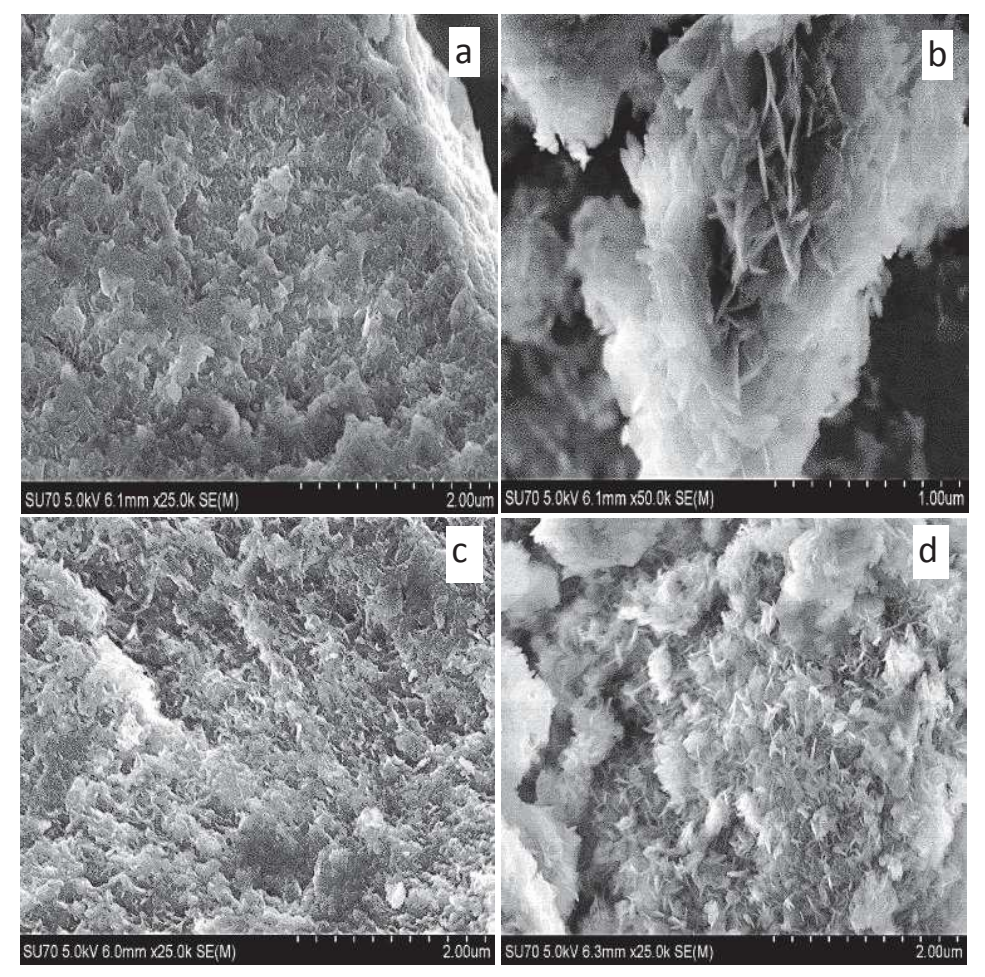

Fig. 12. SEM micrographs of a) $\mathrm{Mg} / \mathrm{Al} / \mathrm{Ce} 1 \mathrm{~mol} \% \mathrm{LDH}$ synthesized by co-precipitation method and b) reconstructed $\mathrm{Mg} / \mathrm{Al} / \mathrm{Ce} 1 \mathrm{~mol} \% \mathrm{LDH}$ c) $\mathrm{Mg} / \mathrm{Al} / \mathrm{Ce} 1 \mathrm{~mol} \% \mathrm{LDH}$ and d) $\mathrm{Mg} / \mathrm{Al} / \mathrm{Ce} 10$ mol\% LDH synthesized by sol-gel method 